\title{
The Ventral Pallidum and Hedonic Reward: Neurochemical Maps of Sucrose "Liking" and Food Intake
}

\author{
Kyle S. Smith and Kent C. Berridge \\ Department of Psychology, University of Michigan, Ann Arbor, Michigan 48109
}

\begin{abstract}
How are natural reward functions such as sucrose hedonic impact and the motivation to eat generated within the ventral pallidum (VP)? Here, we used a novel microinjection and functional mapping procedure to neuroanatomically localize and neurochemically characterize substrates in the VP that mediate increases in eating behavior and enhancements in taste hedonic "liking" reactions. The $\mu$-opioid agonist D-Ala ${ }^{2}-\mathrm{N}$-Me-Phe ${ }^{4}$-Glycol ${ }^{5}$-enkephalin (DAMGO) caused increased hedonic "liking" reactions to sucrose only in the posterior VP but conversely suppressed "liking" reactions in the anterior and central VP. DAMGO similarly stimulated eating behavior in the posterior and central VP and suppressed eating in the anterior VP. In contrast, the $\mathrm{GABA}_{\mathrm{A}}$ antagonist bicuculline increased eating behavior at all VP sites, yet completely failed to enhance sucrose "liking" reactions at any site. These results reveal that VP generation of increased food reward and increased eating behavior is related but dissociable. Hedonic "liking" and eating are systematically mapped in a neuroanatomically and neurochemically interactive manner in the VP.
\end{abstract}

Key words: hedonics; feeding; GABA; opioid; treading; affect; palatability; ventral pallidum

\section{Introduction}

The ventral pallidum (VP) is a focal point for brain limbic circuits (Heimer and Wilson, 1975; Mogenson et al., 1980) and an important substrate for natural reward and drug addiction (Cromwell and Berridge, 1993; Johnson et al., 1996; Kalivas and Nakamura, 1999; Stratford et al., 1999; Swanson, 2000; Watts, 2000; Berthoud, 2002; June et al., 2003; Caille and Parsons, 2004; Insel and Fernald, 2004; Koob, 2004; Tindell et al., 2004). The VP receives compressed reward signals from the nucleus accumbens and other forebrain limbic structures as well as ascending dopamine projections and gustatory inputs (Churchill et al., 1990; Zahm and Heimer, 1990; Heimer et al., 1991; Klitenick et al., 1992; Groenewegen et al., 1993; Usuda et al., 1998). In turn, the VP projects reciprocally to limbic structures and onward to medial thalamus for relay to prefrontal and insular cortex, etc. (Young et al., 1984; Grove, 1988; Groenewegen et al., 1993, 1999; Churchill and Kalivas, 1994; Churchill et al., 1996).

Crucially important to food reward, the VP may be the only brain structure where extensive neuronal cell death abolishes normal hedonic "liking" reactions to sweet tastes (e.g., tongue protrusions) and replaces them with aversive reactions (e.g., gapes) in addition to causing aphagia (Morgane, 1961; Schallert and Whishaw, 1978; Cromwell and Berridge, 1993). Lesions of

Received Feb. 17, 2005; revised July 20, 2005; accepted Aug. 7, 2005.

This work was supported by grants from the National Institutes of Health (NIH) (DA015188 and MH63649) and the National Science Foundation (IBN 0091661) to K.C.B. K.S.S. was supported by NIH training Grant DC00011. We thank Benjamin Long, Andrew Vosko, and Corey Lake for laboratory assistance and Sarah Winans Newman for guidance on neuroanatomy.

Correspondence should be addressed to Kyle S. Smith, Department of Psychology, University of Michigan, 530 Church Street, Ann Arbor, MI 48109-1109. E-mail: kyless@umich.edu.

DOI:10.1523/JNEUROSCI.1902-05.2005

Copyright $\odot 2005$ Society for Neuroscience $\quad$ 0270-6474/05/258637-13\$15.00/0 the VP also impair pursuit for food reward (Johnson et al., 1996) and attenuate sucrose-conditioned place preference (McAlonan et al., 1993). In normal rats, VP neurons respond electrophysiologically to sucrose reward (Tindell et al., 2004) and support electrical self-stimulation (Panagis et al., 1995).

Exactly how does the VP contribute to generating reward hedonic impact or the motivation to eat? Signals from nucleus accumbens to the VP are carried by spiny neuron projections that release GABA and opioid neurotransmitters (Mansour et al., 1988; Chrobak and Napier, 1993; Mitrovic and Napier, 1995; Olive et al., 1997; Napier and Mitrovic, 1999). $\mu$-Opioid neurotransmission in several brain structures is regarded as important for mediating eating and taste hedonic impact (Cooper and Kirkham, 1993; Kelley et al., 1996; Peciña and Berridge, 2000; Berridge, 2003; Levine and Billington, 2004). GABA $\mathrm{A}$ antagonist microinjections in the VP also produce increases in eating behavior (Stratford et al., 1999), and some effects of $\mu$-opioid agonists and $\mathrm{GABA}_{\mathrm{A}}$ antagonists in the VP may overlap (Chrobak and Napier, 1993).

Here, we neurochemically map localization of reward and appetitive functions within the VP by plotting functional effects of drug microinjections and using local Fos plumes to estimate the spread of functional activation. Microinjections causing local $\mu$-opioid activation or $\mathrm{GABA}_{\mathrm{A}}$ blockade were compared at VP sites regarding their ability to (1) alter hedonic "liking" reactions to sucrose taste and (2) elicit increases in eating. Our results demonstrate localization in posterior VP of an opioid hedonic site as well as gradients for generating liking and eating behavior and a more highly distributed but functionally specialized GABAergic modulation of appetitive function. This neuroanatomically and neurochemically interactive mapping may carry implications for understanding the roles of VP subcircuits in reward and desire. 


\section{Materials and Methods}

Maps of "liking" taste reactivity patterns and eating behavior functions were constructed by assessing the spread of functional activation caused by drug microinjections based on plumes of Fos-like protein immunoreactivity around local microinjection sites. The intensity of drug-evoked behavioral effects was plotted onto maps of the VP, based on observed enkephalin staining (to identify VP boundaries) and stereotaxic atlas sections (Paxinos and Watson, 1998) using symbol sizes based on observed Fos plumes. Separate D-Ala ${ }^{2}-\mathrm{N}-\mathrm{Me}-\mathrm{Phe}^{4}-\mathrm{Glycol}^{5}$-enkephalin (DAMGO) and bicuculline maps were constructed for "liking" (hedonic taste reactivity) and eating functions. Experiment 1 assessed behavioral affective "liking" reactions to the hedonic impact of sweet taste. Experiment 2 assessed the effect of microinjections on increases in eating duration and food intake as well as increases in defensive forepaw treading, locomotion, and digging behaviors.

\section{Experiment 1: taste reactivity (sucrose "liking") after VP DAMGO or bicuculline}

Surgery. Male Sprague Dawley rats $(n=30)$ were implanted with bilateral stainless-steel guide cannulas staggered along the anteroposterior (AP) extent of the VP. Rats were pretreated with $0.2 \mathrm{ml}$ of atropine sulfate and anesthetized with $80 \mathrm{mg} / \mathrm{kg}$ ketamine $\mathrm{HCl}$ and $10 \mathrm{mg} / \mathrm{kg}$ xylazine. Rats were positioned in a stereotaxic apparatus (David Kopf Instruments, Tujunga, CA) and implanted with chronic bilateral microinjection guide cannulas (23 gauge; stainless steel) positioned $2 \mathrm{~mm}$ above target sites in the VP. VP microinjection sites were spaced evenly to cover $>80 \%$ volume of the VP, excluding caudal tubercular extensions: AP, 0.7 to -1.2 $\mathrm{mm}$; mediolateral (ML), $\pm 2.0-3.2 \mathrm{~mm}$; dorsoventral (DV), -5.8 to $-6.4 \mathrm{~mm}$ (plus $-2.0 \mathrm{~mm}$ injector tip) (Paxinos and Watson, 1998). Additional rats received control microinjection sites in other adjacent structures dorsal, medial, or caudal to the VP, such as neostriatum $(-0.25 \mathrm{AP}$, $\pm 2.0 \mathrm{ML},-3.5 \mathrm{DV})$, lateral hypothalamus ( $-1.3 \mathrm{AP}, \pm 1.6 \mathrm{ML},-6.2 \mathrm{DV})$, lateral preoptic area $(-0.90 \mathrm{AP}, \pm 1.6 \mathrm{ML},-6.2 \mathrm{DV})$, or substantia innominata (1.4 AP, $\pm 2.6 \mathrm{ML},-6.0 \mathrm{DV})$. As far as possible, site positions in the VP were kept bilaterally symmetrical on both sides of the brain. Guide cannulas were anchored to the skull with four bone screws and acrylic cement, and obturators were inserted in guide cannulas to prevent occlusion. Rats were allowed to recover for at least $7 \mathrm{~d}$ before behavioral testing.

In the same surgery, all rats were additionally implanted with bilateral oral cannulas [polyethylene-100 (PE-100) tubing] to permit subsequent oral infusions of sucrose solutions for taste reactivity testing. Oral cannulas enter the mouth lateral to the first maxillary molar, travel beneath the zygomatic arch, and exit the dorsal head near the skull screws (Grill and Norgren, 1978; Grill and Berridge, 1985). Oral cannulas did not disrupt normal eating.

Drugs and VP microinjections. The $\mu$-opioid agonist DAMGO and the $\mathrm{GABA}_{\mathrm{A}}$ antagonist bicuculline methbromide (Sigma, St. Louis, MO) were separately dissolved in sterile water (Abbott Labs, North Chicago, IL). Each rat received bilateral microinjections of $0.5 \mu \mathrm{l}$ per side of one drug or vehicle on a particular test day. Tests were spaced at least $48 \mathrm{~h}$ apart.

Microinjections were made using a stainless-steel injector cannula (29 gauge), extending $2.0 \mathrm{~mm}$ beyond the ventral end of the guide cannulas, connected to PE-20 tubing and a syringe pump. Rats were handheld gently and infused bilaterally with a volume of $0.5 \mu \mathrm{l}$ at a rate of 0.30 $\mu \mathrm{l} / \mathrm{min}$. Microinjector tips were held in place for an additional $1 \mathrm{~min}$ after infusion to allow drug diffusion, and then obturators were reinserted and the animal was placed in the testing chamber.

Taste reactivity testing. The hedonic impact of tastes is reflected in behavioral affective taste reactivity patterns ("liking" reactions to sucrose taste), which include orofacial reactions of rats such as licks or gapes that are homologous to human affective facial expressions (Grill and Norgren, 1978; Grill and Berridge, 1985; Berridge, 2000; Steiner et al., 2001) (see video examples, available at www.jneurosci.org as supplemental material). We tested affective orofacial reactions of rats to orally infused sucrose solution after VP microinjections of either DAMGO $(0.01,0.1$, $0.25 \mu \mathrm{g})$ or bicuculline $(0.1,0.2 \mu \mathrm{g}$ ) [doses based on Johnson et al. (1993) and Stratford et al. (1999)] or vehicle.

Drugs and doses were assigned to rats based on two essential goals. First, we tested each rat using a within-subjects design to contrast
DAMGO and bicuculline effects, because a major goal of our study was to compare neurochemical patterns of localization of function in the VP. Within-subject comparison of drug effects ensured that observed neurochemical differences were not caused by between-subject individual variation in cannula placement. Second, it was necessary to limit the total number of microinjections to no more than four per rat to avoid local damage. Therefore, each rat was assigned three or four drug/dose combinations (including at least one DAMGO dose, one bicuculline dose, and a vehicle microinjection) in a way that covered all doses and counterbalanced combinations across rats. To ensure that order effects did not distort our data (e.g., because of gradual local damage), microinjection order (day of test) was statistically analyzed as a factor and ruled out before conducting subsequent analyses for drug, dose, or site factors.

After each VP microinjection, a taste reactivity test was performed at $15 \mathrm{~min}$ and repeated at 30 and $60 \mathrm{~min}$ after the microinjection to follow the time course of hedonic effects. Each test lasted $1 \mathrm{~min}$, and time points were chosen to coincide with maximal eating effects in experiment 2 . To infuse sucrose into the mouth, before each test, a $1 \mathrm{ml}$ syringe containing sucrose solution $(1.0 \% ; 0.03 \mathrm{M})$ was attached via hollow tubing (PE-50 connected to a PE-10 delivery nozzle) to a single oral cannula and placed in a syringe pump. In each taste reactivity test, a $1 \mathrm{ml}$ volume of sucrose was infused in 1 min duration, while taste reactivity responses were videorecorded. A close-up video camera recorded all orofacial responses via an angled mirror placed underneath the transparent floor.

Taste reactivity video scoring. Hedonic, aversive, and neutral response patterns were later scored off-line in slow motion ( $1 / 30 \mathrm{~s}$ frame by frame to $1 / 10$ th actual speed) using established behavioral classifications and time bin scoring procedures developed to assess hedonic versus aversive taste valuation (Grill and Berridge, 1985; Berridge, 2000). Hedonic responses included rhythmic midline tongue protrusions, lateral tongue protrusions, and paw licks. Aversive responses included gapes, head shakes, face washes, forelimb flails, and chin rubs. Neutral responses, which are less consistently linked to hedonic/aversive taste valuation, included passive dripping of solution out of the mouth, ordinary grooming, and rhythmic mouth movements. All video analyses were conducted blind to the microinjection drug/vehicle condition.

A time bin scoring procedure was used to ensure that taste reactivity components of different relative frequency still contributed equally to the final affective hedonic/aversive totals (Berridge, 2000). For example, rhythmic mouth movements, passive dripping of solution, paw licking, and grooming reactions typically occur in long bouts and were thus scored in $5 \mathrm{~s}$ time bins ( $5 \mathrm{~s}$ equals one bout occurrence). Tongue protrusions and chin rubs, which occur in shorter bouts, were scored in $2 \mathrm{~s} \mathrm{time}$ bins. The other behavioral components (lateral tongue protrusions, gapes, forelimb flails, head shakes) typically occur in discrete events and were thus scored as single occurrences each time they occurred (e.g., one gape equals one occurrence). Individual rat totals were calculated for hedonic versus aversive categories by adding all response scores within an affective category for that rat. An hedonic "liking" reaction total was the sum of scores for lateral tongue protrusions, rhythmic tongue protrusions, and paw licks. An aversive "disliking" reaction total was the sum of gapes, head shakes, face washes, forelimb flails, and chin rubs.

Histology. After the completion of testing, brains were prepared for one of three analyses: (1) densities and diameters were measured for local Fos plumes caused by microinjections of drugs or vehicle in rats not used for behavioral tests; (2) VP boundaries were verified by enkephalin staining for use in defining map borders; (3) microinjection centers were mapped by ink microinjection and cresyl violet staining in rats used for behavioral testing.

Fos-like protein immunohistochemistry. Fos plumes were measured in rats that were microinjected bilaterally in posterior VP with the most behaviorally effective doses of $0.01 \mu \mathrm{g}$ of DAMGO or $0.2 \mu \mathrm{g}$ of bicuculline or vehicle. Seventy-five minutes after microinjection, rats were anesthetized deeply with sodium pentobarbital before transcardial perfusion. Brains were removed and placed in $4 \%$ formaldehyde for $2 \mathrm{~h}$, placed in $30 \%$ sucrose overnight, and then sectioned at $50 \mu \mathrm{m}$ and stored in $0.2 \mathrm{M}$ $\mathrm{NaPb}, \mathrm{pH}$ 7.4. To visualize Fos-like immunoreactivity, we used the avidin-biotin procedure (Hsu et al., 1981). Brain sections were immersed in blocking solution [ $3 \%$ normal goal serum (NGS) and $0.3 \%$ Triton X-100 
in Tris PBS (TPBS)] for $1 \mathrm{~h}$ and then incubated at room temperature for $24 \mathrm{~h}$ with a rabbit polyclonal antiserum directed against the N-terminal region of the Fos gene (dilution of 1:5000 in TPBS, $1 \%$ NGS, and $0.3 \%$ Triton X-100; Sigma). To reduce background staining, the antiserum was preabsorbed with acetone-dried rat liver powder overnight at $4^{\circ} \mathrm{C}$. After the primary antibody incubation, tissue was exposed to goat anti-rabbit, biotinylated secondary IgG (diluted 1:200; Santa Cruz Biochemicals, Santa Cruz, CA) and then to avidin-biotin-peroxidase complex for $1 \mathrm{~h}$ at room temperature. A nickel diaminobenzidine (Nickel-DAB) glucose oxidase reaction was used to visualize Fos-like immunoreactive cells. Finally, sections were washed in Tris buffer, mounted from doubledistilled $\mathrm{H}_{2} \mathrm{O}$, air-dried, dehydrated in alcohol, cleared in xylene, and coverslipped. Fos-like immunoreactivity was visualized using a Leica (Nussloch, Germany) microscope coupled to a SPOT RT slider (Diagnostic Instruments, Sterling Heights, MI) using SPOT software (SPOT version 3.3).

Fos plume maps of drug-induced local activation spread. Our procedure for measuring Fos plumes immediately surrounding a local microinjection site that are induced by drug was modified slightly from one described previously (Peciña and Berridge, 2000). Briefly, Fos-labeled cells on tissue surface with $5 \times-40 \times$ magnification were counted individually within blocks $(125 \times 125 \mu \mathrm{m})$ at point locations spaced at $125 \mu \mathrm{m}$ intervals along each of seven radial arms emanating from the center of the microinjection site $\left(45,90,135,180,225,270,315^{\circ}\right)$ (see Fig. 1).

Fos densities were measured (1) in normal VP tissue of brains without a microinjection cannula to assess normal baseline expression, (2) around the site of vehicle microinjections to assess cannula track and vehicle-induced Fos baseline expression, and (3) around the site of DAMGO and bicuculline microinjections to assess drug-induced elevations of local Fos expression (see Fig. 1).

Fos plumes surrounding drug microinjections were mapped as zones of intense or moderate elevation of Fos expression, identified in two ways: (1) as absolute increases over VP normal levels [elevation by 10 times (intense) or five times (moderate) normal tissue counts sampled in the absence of any cannula track and (2) as vehicle-relative increases caused by drug (elevation by five times or two times over vehicle microinjection-induced levels at equivalent point locations around drug vs vehicle microinjection tracks] (see Fig. 1).

Leu-enkephalin immunocytochemistry. The location of VP boundaries were confirmed visually based on enkephalin staining to draw map borders (see Fig. 1), because the VP contains a higher density of enkephalinstaining fibers and puncta than neighboring structures (Zahm et al., 1985; Zahm, 1989; Holt and Newman, 2004). After perfusions, brains were removed and placed in $4 \%$ formaldehyde for $2 \mathrm{~h}$ and then placed in $30 \%$ sucrose overnight. The brains were sectioned in horizontal or coronal planes on a sliding microtome at $50 \mu \mathrm{m}$ and collected in well staining trays containing $0.2 \mathrm{M} \mathrm{NaPb}, \mathrm{pH}$ 7.4. Sections were rinsed in $0.1 \mathrm{M} \mathrm{KPBS}$, $\mathrm{pH} 7.2$ (three times; $10 \mathrm{~min}$ ) and incubated for 1-2 $\mathrm{h}$ in NGS solution containing KPBS and $10 \%$ Triton X-100. Sections were again rinsed with KPBS and incubated for $24 \mathrm{~h}$ in rat leu-enkephalin antibody (rabbit polyclonal; Pennsylvania Laboratories, Belmont, CA) solution at a concentration of 1:5000 containing KPBS and 10\% Triton X-100. After a KPBS rinse, the sections were then exposed to a goat anti-rabbit, biotinylated secondary IgG (Santa Cruz Biochemicals) diluted 1:200 and then to the avidin-biotin-peroxidase complex for $1 \mathrm{~h}$. To visualize leuenkephalin, we used a Nickel-DAB glucose oxidase reaction. Sections were washed, mounted, dried, and visualized as described above for Fos immunocytochemistry.

Mapping procedure of microinjection effects for localization of function. Rats from behavioral experiments were anesthetized deeply with sodium pentobarbital, microinjected with ink $(0.5 \mu \mathrm{l})$, and perfused transcardially with buffered saline followed by $4 \%$ paraformaldehyde solution. Brains were removed, postfixed in $4 \%$ paraformaldehyde, cryoprotected with buffered $20 \%$ sucrose solution, coronal sectioned $(40-60 \mu \mathrm{m})$, mounted on slides, and stained with cresyl violet. Cannula placements were first located by measuring how far ventral ink extended directly below a microinjection cannula and identifying the midway point on the vertical line between the bottom of the cannula and the ventral edge of the ink $180^{\circ}$ below. This center point was localized within a $0.1 \mathrm{~mm}$ margin of error and plotted on the coronal atlas page that best fit that slice. The dorsoventral and mediolateral coordinates were read off the coronal atlas axes ( $\pm 0.1 \mathrm{~mm}$ accuracy) (Paxinos and Watson, 1998), and the anteroposterior coordinate of the point was taken either from the coronal atlas page (if the slice fit the page closely) or from the midpoint between two adjacent atlas pages (if the slice appeared intermediate between atlas sections; $\pm 0.2 \mathrm{~mm}$ accuracy). Initial placements were made in the coronal plane because the coronal plane has been most thoroughly mapped in available standard atlases, and its greater degree of detail facilitated more precise mapping of site centers. The three coordinates of the center point were then transformed into horizontal and sagittal atlas locations to provide three-dimensional maps of microinjection centers that were accurate to 0.01-0.2 mm. Map boundaries of VP used for these placements were guided additionally by our observations of leuenkephalin immunolabeling in sections sliced in the same plane as the maps (see Fig. 1).

Maps for localization of function were constructed by computing a magnitude behavioral effect on "liking" reactions (or on eating behavior in experiment 2) produced by a drug microinjection at each site. The magnitude of behavioral effect for each drug was calculated as a difference score compared with control magnitude after vehicle microinjection at the same site in the same rat. The functional magnitude of the drug/dose effect at that site was plotted at its mapped site in the VP using symbols based on Fos plume size and colors based on behavioral effect for that rat/site/dose (see Fig. 2).

Statistical analysis. Behavioral effects of DAMGO and bicuculline were first analyzed for microinjection order effects (to assess whether our data were distorted by gradually accumulating damage or other order effects). After ruling out significant order effects and interactions of order with drug or dose, behavioral data for each site, drug, and dose were analyzed using a two-way ANOVA (drug/dose-by-site location), followed by oneway ANOVAs or Bonferroni's post hoc comparisons. Data from rats with control site placements in structures outside of the VP were analyzed separately.

\section{Experiment 2: VP DAMGO or bicuculline elicitation of \\ motivated behaviors}

Subjects. Male Sprague Dawley rats $(n=44 ; 300-420 \mathrm{~g})$ were group housed $\left(\sim 21^{\circ} \mathrm{C} ; 12 \mathrm{~h}\right.$ light/dark cycle) in opaque plastic tub cages containing wood shaving bedding. Food (Purina Rat Chow; Purina Mills, St. Louis, MO) and water were available ad libitum. Rats were implanted as described above with bilateral microinjection guide cannulas in the VP or in anatomically dorsal, medial, or posterior brain structures to control for drug diffusion effects (neostriatum, anterior lateral hypothalamus, and lateral preoptic area or substantia innominata). Rats were allowed at least 1 week recovery before behavioral testing.

Behavioral testing. Rats were habituated to the testing conditions for $3 \mathrm{~d}$ before behavioral testing and received a mock injection of vehicle on the final habituation day. Drug doses were the following: bicuculline (0.0, $0.05,0.1,0.2 \mu$ g per side $)$ or DAMGO $(0.0,0.01,0.1,0.25 \mu$ g per side $)$ [doses from Johnson et al. (1993) and Stratford et al. (1999)]. Drugs and doses were assigned on the same basis as in experiment 1 .

Behavioral testing was conducted in 60 min sessions to measure food intake, actual eating behavior, and other spontaneous motivated behaviors. Rats were tested in transparent tub cages containing wood shaving bedding, which were identical in size to home cages $(23 \times 20 \times 45 \mathrm{~cm})$. Premeasured food pellets (Purina Rat Chow) were placed on the cage floor, and a spout of tap water was available. Amount of food eaten was recorded by weight at the end of the experiment (crumbs were noted and retrieved if present). Behavior was videotaped during testing and later scored off-line in slow motion by a researcher blind to the drug microinjection condition. Videos were scored for (1) duration of eating behavior (in seconds), (2) number of cage crosses, (3) number of rears, (4) number and direction of paw-treading bouts (a species-specific defensive behavior, composed of alternating or simultaneous thrusts by the two paws, which throw woodchips forward in front of the rat, sometimes accompanied by head burying, emitted in $1-5 \mathrm{~s}$ bouts; see treading and digging video examples in supplement material, available at www. jneurosci.org), (5) number of bouts of food carrying (grasping and 
transport of food pellets), and (6) number of bouts of digging behavior (hunched posture with a forward center of gravity and a thrusting of the forepaws toward the side or underneath the body, which push woodchips aside or backward but not forward).

Histology. Histological verification of cannula placement and construction of placement maps followed procedures used in the first experiment.

Statistical analysis. Effects of DAMGO and bicuculline on each behavior were analyzed separately using a two-way ANOVA (drug dose-by-injection location), followed by Bonferroni's post hoc comparisons or one-way ANOVAs. Anatomical control data from rats with cannula placements outside of the VP were analyzed separately.

\section{Results \\ Fos plumes: identifying zones of local neuronal activation}

We used a functional mapping procedure based on Fos protein activation in neurons around the site of VP microinjection to identify local Fos plumes. Drug-induced local expression of immediate early gene transcription immediately surrounding a microinjection site is one method to assess the distance and intensity of drug action on local tissue, at least for drugs that induce Fos transcription such as DAMGO and bicuculline. Fos expression in a local neuron might reflect either direct drug action on receptors on that neuron or else indirect action via local circuits from adjacent neurons containing receptors. In either case, the Fos plume reflects a local zone of functional modulation induced by the drug and provides quantitative information on intensity and size of the local activation zone. The boundaries of the plume reveal where the drug has the most intense functional impact, even if drug molecules spread further beyond the plume in lower concentrations insufficient to trigger gene transcription. Thus, a Fos plume provides objective information on the extent of tissue activation most likely to mediate functional effects of drug microinjections.

The spread of local functional activation caused by drug microinjections was bracketed between high and low criteria for intense versus moderate elevation of Fos expression (Fig. 1). An inner zone of intense Fos elevation was defined as the mean radius within which (1) absolute Fos expression was increased by 1 order of magnitude over normal tissue levels, and (2) relative Fos expression was increased by $2 \times$ over the levels produced at equivalent locations after vehicle microinjections. An outer zone of moderate Fos elevation was defined at the mean radius within which (1) absolute Fos expression was increased by $5 \times$ (but not $10 \times$ ) over normal tissue levels, and (2) relative Fos expression was increased by $5 \times$ over the level of equivalent points after vehicle locations [Note: the reason why our outer zone used a higher vehicle-
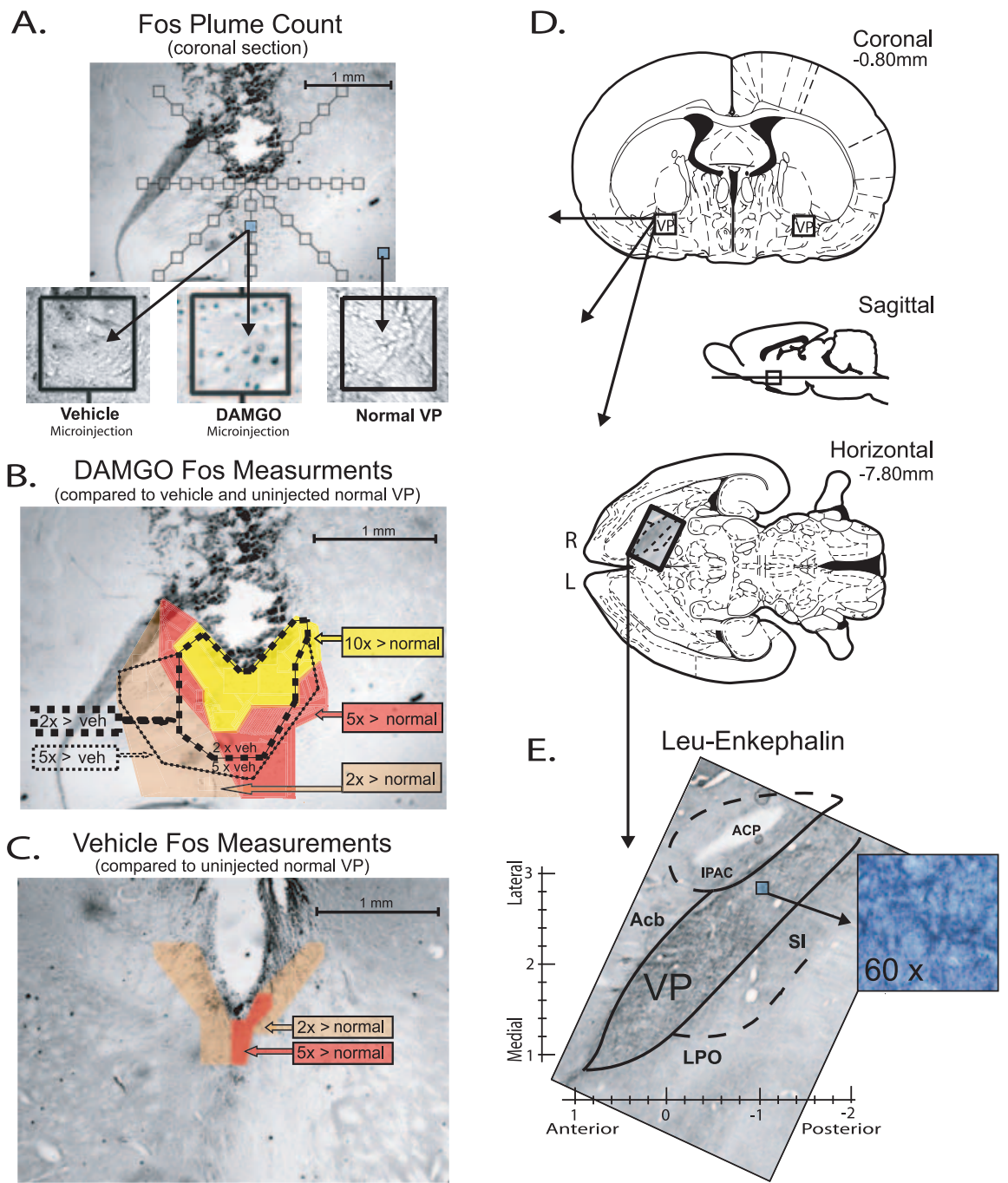

Figure 1. Fos plumes and VP perspectives. $\boldsymbol{A}$, Coronal section showing point sample positions used to identify local Fos plumes around microinjection site $(125 \times 125 \mu \mathrm{m}$ blocks on radial arms extending from center; $5 \times$ magnification). Insets show examples of Fos densities after vehicle or DAMG0 microinjection in posterior VP $(0.01 \mu \mathrm{g}$ in $0.5 \mu \mathrm{l}$; $75 \mathrm{~min}$ after microinjection; $40 \times$ magnification) or from uninjected normal VP tissue. $\boldsymbol{B}$, Example of Fos plume after $0.01 \mu \mathrm{g}$ DAMG0 microinjection, as mapped by several criteria. Colors show zones of absolute Fos expression elevation above normal VP tissue levels after DAMGO microinjection (yellow, absolute increases of $>10 \times$; red, $>5 \times$; orange, $>2 \times$ ). Dotted lines show zones of relative Fos increase compared with after vehicle (veh) microinjection levels measured at equivalent points surrounding cannula site (thick dotted line, $>2 \times$ relative increase; thin dotted line, $>5 \times)$. Bicuculline caused Fos plumes of similar size $(0.2 \mu \mathrm{g}$; data not shown). $\boldsymbol{C}$, Moderately low Fos expression after vehicle microinjection (but elevated because of damage or vehicle pressure/composition over normal spontaneous Fos levels). D, Coronal, sagittal, and horizontal planes containing VP [from Paxinos and Watson (1998)]. $\boldsymbol{E}$, Entire VP and boundaries are visible in single horizontal section stained for leu-enkephalin, and observed boundaries were used to adjust VP atlas boundaries when mapping VP functions ( $5 \times$ magnification). Inset shows $60 \times$ magnification of posterior VP. ACP Posterior limb of the anterior commissure; IPAC, interstitial nucleus of the posterior limb of the anterior commissure; Acb, nucleus accumbens; SI, substantia innominata; LP0, lateral preoptic area.

relative threshold than the inner zone was that a vehicle microinjection induces some Fos expression in a small centrally restricted inner zone, perhaps because of pressure of the microinjection or irritation from cannula-induced damage. The resulting slight elevation in inner zone vehicle baseline (above normal tissue baseline) imposed a ceiling on drug-induced Fos expression in this central zone that limited relative increases to under $5 \times$ (even if drug caused a $>10 \times$ absolute increase).]

The mean inner zone of intense DAMGO Fos elevation $(0.01$ $\mu \mathrm{g}$ ) was $0.28 \pm 0.04 \mathrm{~mm}$ radius (absolute $10 \times$ increase over normal; relative $2 \times$ increase over vehicle), and the outer zone of low elevation was an additional $0.21 \pm 0.05 \mathrm{~mm}$ radius (absolute 
A.

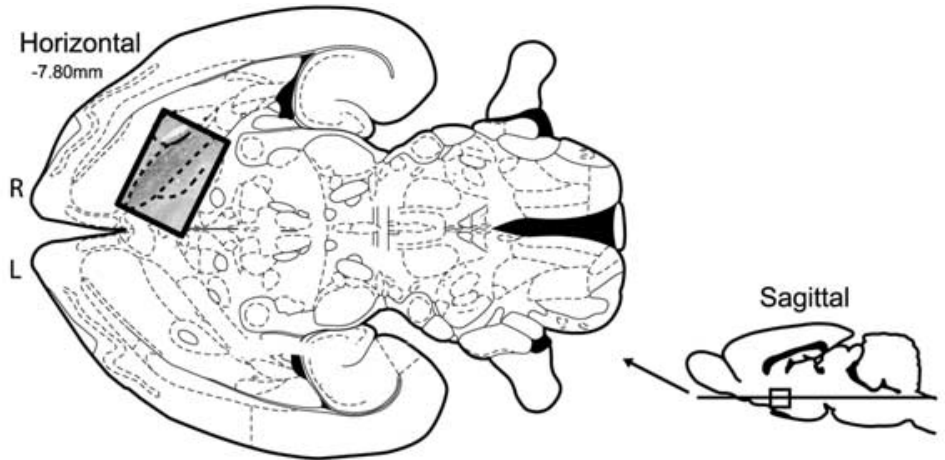

B.

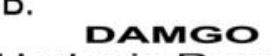
Hedonic Reactions
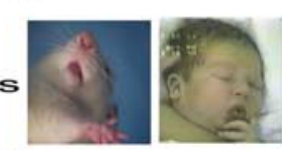

C.

Bicuculline Hedonic Reactions

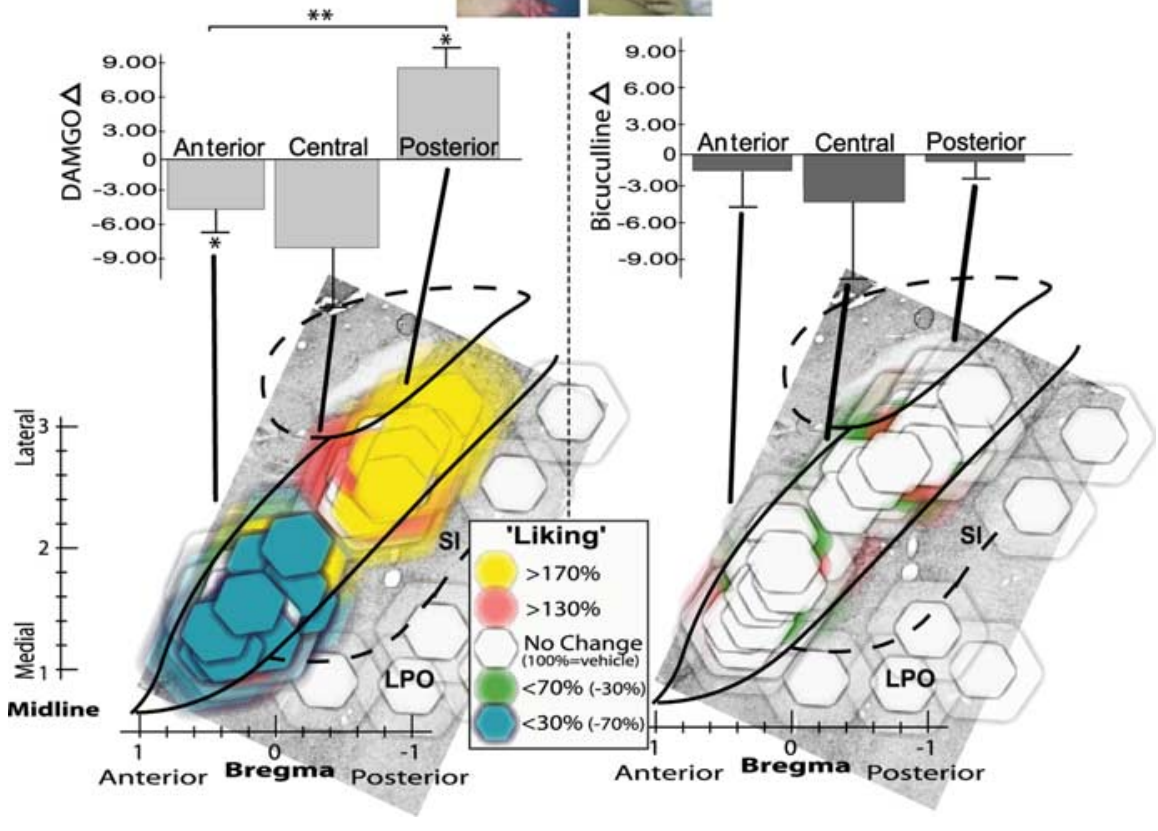

Figure 2. Hedonic "liking" generation maps. Changes in hedonic impact of sucrose caused by VP microinjections of DAMG0 versus bicuculline (assessed by taste reactivity; all doses included). $\boldsymbol{A}$, Location of VP in horizontal and sagittal sections (Paxinos and Watson, 1998). R, Right; L, left. B, Opioid hedonic generation map, DAMGO effects on sucrose "liking." Horizontal view of VP (superimposed on enkephalin stain) shows changes in positive sucrose-elicited "liking" reactions caused by DAMG0 microinjections, expressed as within-subject percentage changes from vehicle microinjections at the same sites (vehicle, 100\%). Bilateral VP sites from left and right brains of each rat are collapsed together here into a unilateral single map of VP (right brain) for better simplicity (all doses represented). Colors denote direction and intensity of "liking" change from vehicle levels, and symbol size shows the diameter of intense Fos plumes ( $10 \times$ elevation above normal; $0.28 \mathrm{~mm}$ radius for $0.01 \mu \mathrm{g}$ DAMG0), surrounded by semitransparent halos that show diameter of moderate Fos plumes $(0.49 \mathrm{~mm}$ radius). Bar graph above shows average intensity of change caused by microinjections in each $1 / 3$ region of VP: anterior, central, or posterior (within-subject difference score of drug minus vehicle; $\left.{ }^{*} p<0.05 ;{ }^{* *} p<0.01\right)$. C, GABA blockade hedonic generation map. Bicuculline effects on sucrose "liking" $(0.2 \mu \mathrm{g}$ bicuculline; otherwise same as $\boldsymbol{B}$ ). Photographs show example hedonic "liking" reactions to sucrose by rat and human infant [modified from Steiner et al. (2001)] (also see "liking" examples in supplemental movies, available at www.jneurosci.org as supplemental material). Error bars represent SEM. SI, Substantia innominata; LPO, lateral preoptic area. (intense activation) to $11 \%$ (moderate/intense activation) of total VP area per plume (percentage of surface area of single section). Although additional work is needed on functional spread, these observations suggest that the entire VP can be covered by plumes of $\sim 10-15$ rats with appropriate microinjection placements using current parameters.

Colors for symbols and halos were assigned to represent the magnitude of behavioral effects produced by drug microinjections at each microinjection site (expressed as a change score compared with the control vehicle effect at that same site). We chose the horizontal plane to map localization of VP functions because the horizontal section allows the entire VP to be viewed on a single map without need to compress data from multiple sections onto a single figure. The VP is most highly extended in its anterioposterior plane. Therefore, in coronal section, multiple maps are needed to represent the entire VP. A single sagittal section captures more of the VP than any coronal section but still requires some compression of data taken from multiple sagittal sections in different mediolateral planes to be represented on a single sagittal figure (see Fig. 6 and supplemental Figs. S1-S3, available at www. jneurosci.org as supplemental material). In contrast, a horizontal section can represent the entire VP in a single plane. For these reasons, we present VP maps primarily in horizontal planes in Figures 2-5, which most accurately show the entire VP and for threedimensional comparison purposes provide multiple coronal maps and a compressed sagittal map in Figure 6 and supplemental Figures S1-S3 (available at www.jneurosci. org as supplemental material). The horizontal structural boundaries of the VP in these maps were adjusted from the published rat brain atlas to fit enkephalin-labeled VP boundaries that we actually observed (Fig. 1) (Paxinos and Watson, 1998).

\section{Experiment 1: DAMGO enhances} sucrose "liking" in an anteroposterior gradient, but bicuculline does not affect "liking"

$5 \times$ increase over normal; relative $5 \times$ increase over vehicle) (Fig. 1). Therefore, colored symbols of $0.28 \mathrm{~mm}$ radius in size were assigned to each microinjection site to represent conservative estimates of intense functional spread, and similarly colored halos of additional $0.49 \mathrm{~mm}$ radius were placed around symbols to represent maximum estimates of moderate spread. Thus, symbols and halos served to bracket the estimated range of tissue activation likely to mediate the mapped microinjection effects. Bicuculline microinjection $(0.2 \mu \mathrm{g})$ caused Fos plumes of similar size (10X absolute zone, $0.29 \mathrm{~mm}$ radius; $5 \times$ absolute zone, 0.56 radius).

Fos expression in $0.5-1.0 \mathrm{~mm}$ diameters correspond to $\sim 6 \%$
Posterior VP $\mu$-opioid activation increases sucrose "liking"

Positive hedonic "liking" reactions (sum of lateral tongue protrusion, rhythmic tongue protrusion, and paw lick scores) elicited by infusions of sucrose solution into the mouth were increased in number by VP microinjections in a way that was both neurochemically and neuroanatomically specific. Hedonic reactions to sucrose were enhanced neurochemically only by DAMGO microinjections $\left(F_{(3,163)}=4.69 ; p<0.01\right)$ (Figs. 2,6$)$ and neuroanatomically only in the posterior third of the VP (ANOVA for drug; $\left.F_{(1,68)}=9.49 ; p<0.01\right)$. Rhythmic tongue protrusion elicited by sucrose taste was the particular hedonic component of 
taste reactivity most enhanced by DAMGO in the posterior VP $(p<0.05)$. Concerning time course, the $>170 \%$ (above vehicle) increase in hedonic "liking" reactions to the taste of sucrose appeared within $15 \mathrm{~min}$ after DAMGO microinjection in the posterior VP $(p<0.05$ compared with vehicle) and persisted for the entire hour after microinjection, remaining significantly elevated over vehicle at the taste reactivity test repeated at both 30 and 60 min tests ( $p<0.05$ for both). Time of test after microinjection was not a significant factor overall $\left(F_{(2,162)}=0.19 ; p=\right.$ 0.83 ), and so subsequent analyses combine over these sampling times (mean responses over the three sucrose infusions).

Posterior location of DAMGO microinjection within the VP was crucial to increased hedonic "liking" reactions compared with other sites $\left(F_{(3,56)}=3.05 ; p<\right.$ $0.05)$, and DAMGO had opposite effects on "liking" reactions at anterior versus posterior VP sites (drug-by-site interaction; $F_{(4,56)}=3.98 ; p<0.01$ ) (Figs. 2, 6). Only in the posterior VP were hedonic reactions enhance by DAMGO; that is, posterior to the interventricular foramen and between the rostral tip of the lateral hypothalamus and the caudal tip of the olfactory tubercle $\left(F_{(1,25)}=5.28 ; p<0.05\right)$. In contrast, in the anterior third of the VP (rostral to the anterior limb of the anterior commissure and to the rostral tip of the globus pallidus) DAMGO actually suppressed positive "liking" reactions below vehicle level $\left(F_{(1,23)}=\right.$ $4.90 ; p<0.05$ ) (Figs. 2, 6), exactly the opposite effect of the posterior VP "liking" enhancement. DAMGO suppression of hedonic "liking" reactions in the anterior VP was characterized by suppressed rhythmic tongue protrusion and lateral tongue protrusion components, which are normally elicited by sucrose infusions (each $p<0.05$ compared with vehicle). In the central VP region (rostral to the interventricular foramen but level or just caudal to the anterior limb of the anterior commissure), DAMGO microinjection did not significantly increase or decrease hedonic reactions from vehicle levels $\left(F_{(1,7)}=2.12\right)$, although a slight trend toward suppressed hedonic reactions was observed $(-43 \%$ DAMGO reduction of hedonic reactions from vehicle).

Concerning dose-response effects on hedonic taste "liking" reactions, in the posterior VP, DAMGO doses $(0.01,0.1,0.25 \mu \mathrm{g})$ did not significantly differ from each other in their magnitude of hedonic increase over vehicle level $\left(F_{(3,25)}=3.00\right)$ (Fig. 4). Both the lowest and highest DAMGO doses (0.01 and $0.25 \mu \mathrm{g})$ caused significant $>170 \%$ increases in positive hedonic reactions to sucrose ( $p<0.05$ for both) (Fig. 4), whereas the intermediate dose $(0.1 \mu \mathrm{g})$ produced a marginal increase $(p=0.09)$. In general, all DAMGO doses in the posterior VP appeared to produce similar increases in positive hedonic "liking" reactions to sucrose taste.

In contrast, the suppression of "liking" reactions in the anterior
VP by DAMGO showed a descending linear dose-response relation$\operatorname{ship}\left(F_{(3,56)}=3.05 ; p<0.05\right)$ (Fig. 4). The second highest dose $(0.1$ $\mu \mathrm{g}$ of DAMGO) in the anterior VP cut hedonic "liking" reactions to sucrose in half (compared with vehicle levels), and the highest 0.25 $\mu \mathrm{g}$ dose reduced positive hedonic reactions almost to zero $(p<0.05$ below vehicle levels for each). This is consistent with the pattern of opioid enhancement of sweetness hedonic impact in the posterior VP but no change or hedonic suppression in the central and anterior VP. The lowest $0.01 \mu \mathrm{g}$ dose failed to alter "liking" reactions, and hedonic suppression by the higher doses $(0.1$ and $0.25 \mu \mathrm{g})$ was greater than suppression by the lowest dose in the anterior VP $(p<0.001)$.

\section{Affectively neutral and aversive reactions}

Neutral reactions (mouth movements and passive drips; neither strongly positive nor aversive in hedonic valence) were sup- 


\section{A. \\ B.}

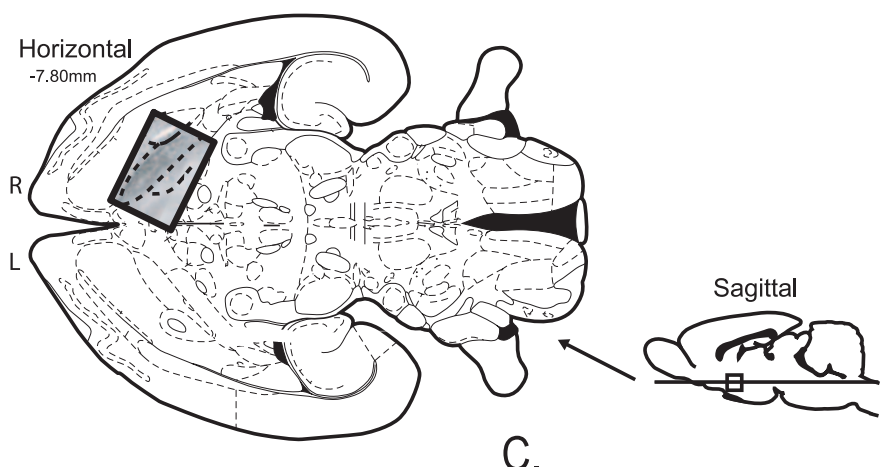

Bicuculline Hedonic Reactions (percent change from vehicle)
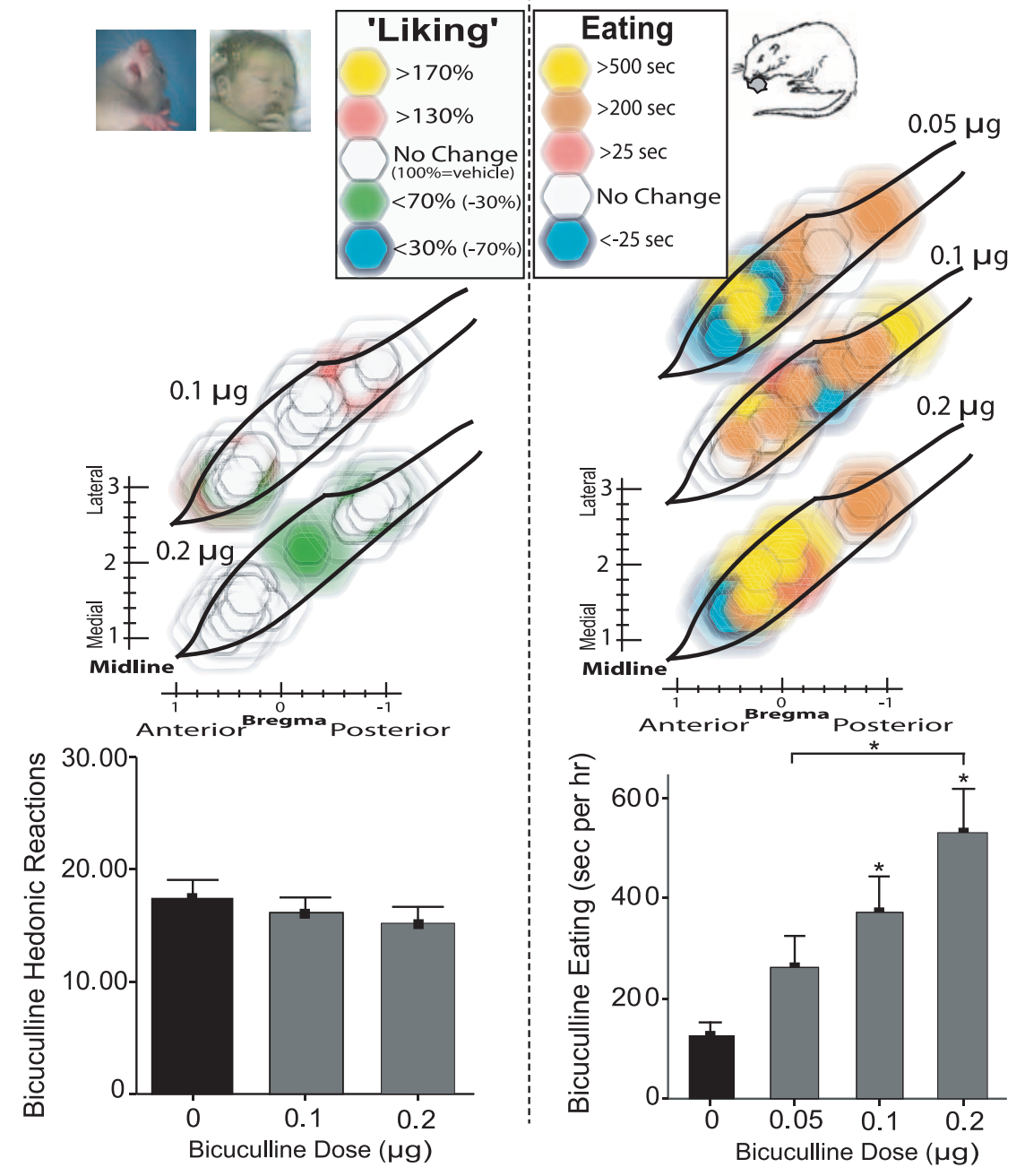

i

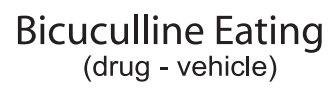

(drug - vehicle)

Figure 4. Functional dose-response VP maps of DAMGO effects on hedonic "liking" and eating behavior. A, Location of VP maps in horizontal and sagittal sections (Paxinos and Watson, 1998) (horizontal insert overlaid with enkephalin stain). R, Right; L, left. $B$, DAMG0 effects on sucrose "liking." Color function maps shows change in hedonic "liking" reactions elicited by sucrose taste after each dose of DAMGO $(0.01,0.1,0.25 \mu \mathrm{g})$ compared with vehicle (percentage change from vehicle, $100 \%$ at same sites). Symbols as in Figures 2 and 3. The bottom bar graph represents number of positive hedonic "liking" reactions after DAMG0 or vehicle in anterior and posterior halves of VP $\left({ }^{*} p<0.05 ; * * 0.01\right)$. C, DAMG0-evoked eating behavior. Color maps show eating durations evoked by each dose of DAMGO $(0.01,0.1,0.25 \mu \mathrm{g})$ compared with vehicle (absolute change). Bar graph represents eating total duration in anterior and posterior VP halves after vehicle or each DAMGO dose. Error bars represent SEM.

Distorting order effects ruled out

Finally, microinjection order (day) was not a significant factor for microinjections either in the posterior VP $\left(F_{(2,14)}=1.17\right)$ or the anterior $\operatorname{VP}\left(F_{(3,14)}=1.37\right)$ nor was there any interaction of order with drug or dose for any of the effects described above (posterior, $F_{(3,23)}=0.49$; anterior, $\left.F_{(4,25)}=1.40\right)$, indicating that our drug or dose effect data were not distorted by gradual damage at the site, tolerance, or other order effects.

\section{$G A B A_{A}$ blockade in the VP fails to affect} sucrose "liking"

In contrast to opioid (DAMGO) effects on hedonic "liking" reactions, GABAergic bicuculline microinjections in the VP completely failed to change hedonic taste reactivity patterns elicited by sucrose at any location (time-averaged ANOVA for drug; $F_{(2,59)}=0.78$ ) (Fig. 2, supplemental Fig. S2, available at www.jneurosci.org as supplemental material). No VP site supported bicuculline changes in positive hedonic reactions $\left(F_{(2,59)}=1.20\right)$. Similarly, bicuculline failed to alter neutral $\left(F_{(2,59)}=0.63\right)$ or aversive $\left(F_{(2,59)}=0.25\right)$ affective reactions to taste at any site or dose (Fig. 5), and there was no interaction between bicuculline and site for any behavioral taste reactions $\left(F_{(3,59)}=0.64\right)$. Thus, it appears that $\mathrm{GABA}_{\mathrm{A}}$ blockade in the VP never causes an increase or other change in the hedonic impact of sweet taste ("liking" reactions) in any subregion.

\section{Control sites outside of the VP}

Rats with cannula sites that bilaterally targeted control structures outside of the VP failed to alter hedonic reactions after any dose of either DAMGO or bicuculline (lateral hypothalamus, $n=$ 3 ; substantia innominata, $n=1$; neostriatum, $n=2$; lateral preoptic area, $n=2$ ) (Fig. 6, supplemental Fig. S2, available at www.jneurosci.org as supplemental material). Thus, the changes in "liking" reactions produced by microinjections in the VP described above appears unlikely to have been mediated by diffusion to these other dorsal, posterior, or posteromedial structures.

\section{Experiment 2: neuroanatomical heterogeneity in the VP for motivated eating elicited by DAMGO and bicuculline microinjection}

pressed by DAMGO at the posterior VP $\left(F_{(3,26)}=3.31 ; p<0.05\right)$ and enhanced at both the central $\left(F_{(1,8)}=10.63 ; p<0.05\right)$ and the anterior $\operatorname{VP}\left(F_{(3,23)}=4.57 ; p<0.05\right)$. Aversive reactions (e.g., gape) to sucrose were typically low (as would be expected for a sweet taste) and were not significantly changed by DAMGO administration at any site.
Eating behavior elicited by $\mu$-opioid activation

VP microinjections of the $\mu$-opioid agonist DAMGO caused eating behavior to nearly double in overall duration compared with vehicle $\left(F_{(3,65)}=9.68 ; p<0.001\right)$ (Fig. 3, supplemental Fig. S1, available at www.jneurosci.org as supplemental material). Measures of food intake (grams consumed) were doubled similarly, 
so we report below only data for eating behavior. Opioid microinjection in the anterior, central, and posterior VP regions produced different effects on eating duration $\left(F_{(2,65)}=8.76 ; p<0.01\right)$. Specifically, DAMGO caused increased eating duration only in the posterior/central two-thirds of the VP (site-by-drug interaction; $F_{(6,65)}=$ 4.06; $p<0.01$ ). DAMGO significantly increased eating duration above vehicle levels at both the posterior VP $(p<0.05)$ and central VP regions $(p<0.05)$ (Fig. 3, supplemental Fig. S1, available at www.jneurosci. org as supplemental material).

When examined in more detail, DAMGO in the posterior VP was observed to increase eating duration $377 \%$ over vehicle, and DAMGO in the central VP increased eating duration by $235 \%$. Finally, when the most extremely anterior tip of the VP was examined separately, in three rats with sites in the most anterior $20 \%$ of the VP (i.e., anterior to the rostral limb of the anterior commissure, at the level of caudal nucleus accumbens), DAMGO in this location actually caused time spent eating to decrease $>10 \%$ below vehicle $\left(n=3 ; t_{(5)}=-2.29 ; p<0.05\right)$ (Fig. 3, supplemental Fig. S1, available at www. jneurosci.org as supplemental material). This indicates that opioid neurotransmission in the far anterior tip of the VP actually suppresses eating below baseline. Together, the posterior $\geq$ central $>$ anterior pattern of opioid-elicited eating indicates an anterioposterior gradient in the VP for the intensity of opioid-induced eating behavior; the more posterior the DAMGO site in the VP, the more eating it causes (Fig. 3, supplemental Fig. S1, available at www.jneurosci.org as supplemental material). The gradient appears to become bipolar and negative in the far anterior tip of VP (Fig. 3, supplemental Fig. S1, available at www.jneurosci.org as supplemental material).

Dose-response analyses were performed separately for anterior versus posterior halves of the VP (after confirming that VP halves differed in amount of DAMGOevoked eating; $F_{(1,35)}=4.98 ; p<0.05$ ) (Fig. 4). Eating duration was increased best by low doses of DAMGO in the posterior VP, where dose was a significant overall factor in the posterior $\operatorname{VP}\left(F_{(3,35)}=4.21 ; p<0.05\right)$ but not the anterior VP $\left(F_{(3,28)}=0.51 ; p=\right.$ 0.68). In the posterior VP, the lowest DAMGO dose $(0.01 \mu \mathrm{g})$ caused the greatest increase in eating duration $(425 \% ; p<0.05)$ (Fig. 4). The higher two posterior doses (0.1, $0.25 \mu \mathrm{g})$ caused smaller increases than the lowest dose $(0.1 \mu \mathrm{g}$, 370\%; $0.25 \mu \mathrm{g}$, 325\%; $p<0.05$ for each) but still elevated eating above vehicle levels $(p<0.05)$. In contrast, in the anterior VP, no DAMGO dose-evoked eating above vehicle levels.

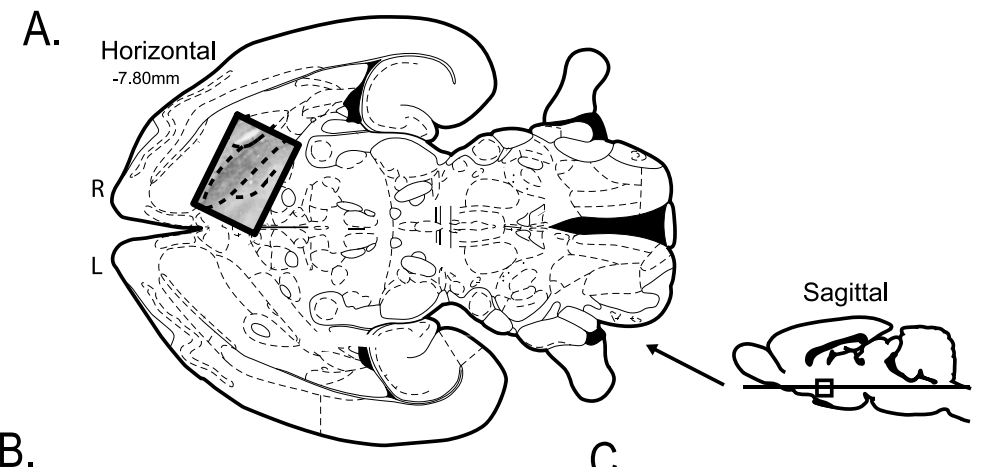
Bicuculline Hedonic Reactions (percent change from vehicle)
Bicuculline Eating (drug - vehicle)

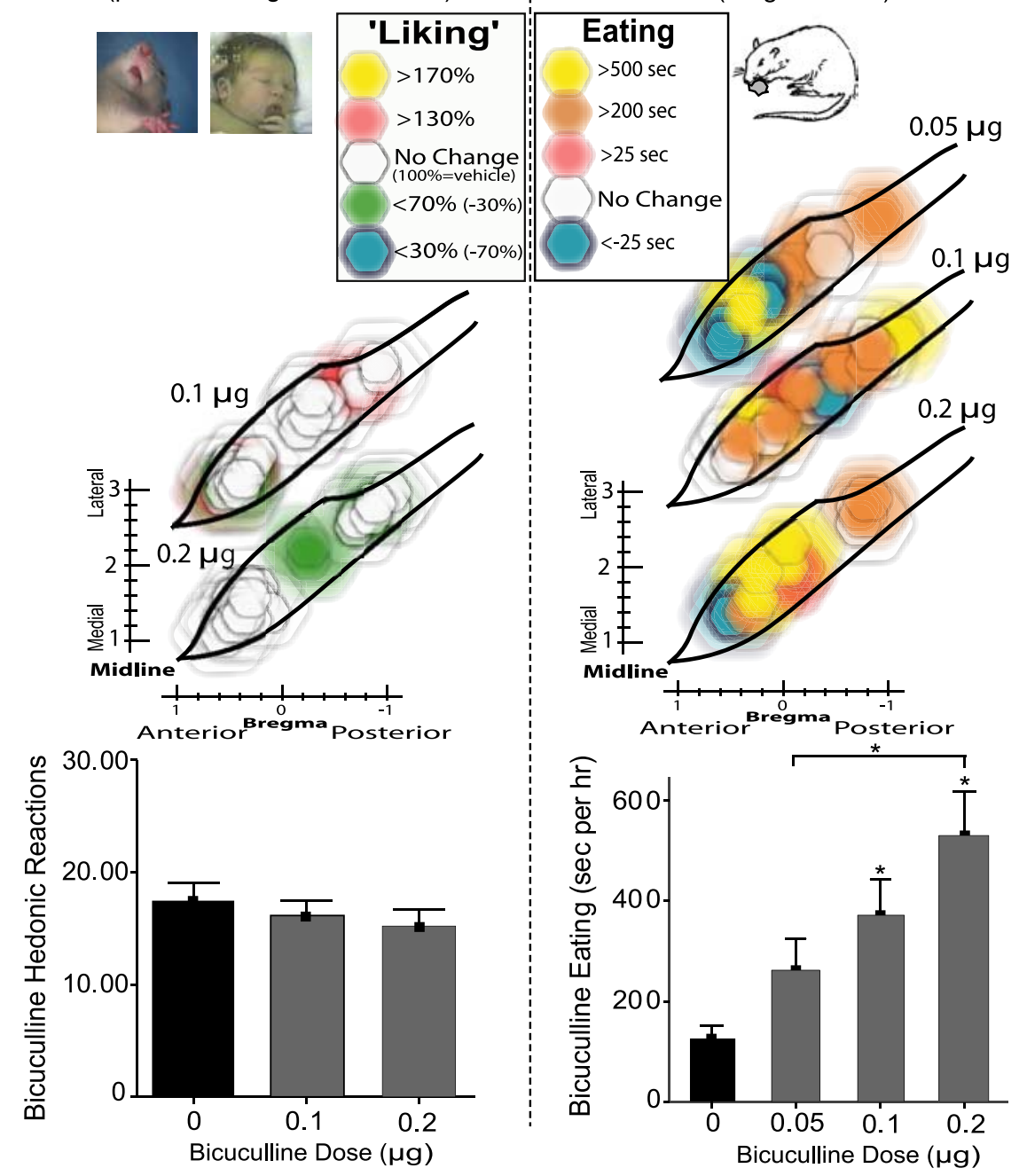

Figure 5. Functional dose-response VP maps of bicuculline effects. $\boldsymbol{A}$, Location of VP maps in horizontal and sagittal sections (Paxinos and Watson, 1998) (horizontal insert overlaid with enkephalin stain). R, Right; L, left. B, Bicuculline sucrose "liking." Color function maps show changes in hedonic "liking" reactions elicited by sucrose taste after each dose of bicuculline $(0.1,0.2 \mu \mathrm{g})$ compared with vehicle (percentage change from vehicle, $100 \%$ at same site). Symbols are as in Figures $2-4$. The bottom bar graph represents total number of positive hedonic "liking" responses to sucrose after bicuculline or vehicle microinjections (no anatomical differences existed for bicuculline eating effects, and so all VP sites were combined). C, Bicuculline-evoked increases in eating behavior. Color maps shows relative increase in eating duration evoked by each dose of bicuculline $(0.05,0.1,0.2 \mu \mathrm{g})$ compared with vehicle at the same site. Bar graph represents cumulative eating durations evoked by vehicle and by each bicuculline dose $\left({ }^{*} p<0.05\right)$. Error bars represent SEM.

\section{Eating behavior elicited by $G A B A_{A}$ blockade}

Bicuculline microinjection in the VP also doubled eating duration overall (mean, $179 \%$ above vehicle; $F_{(3,62)}=6.50 ; p<0.01$ ) (Fig. 3, supplemental Fig. S3, available at www.jneurosci.org as 

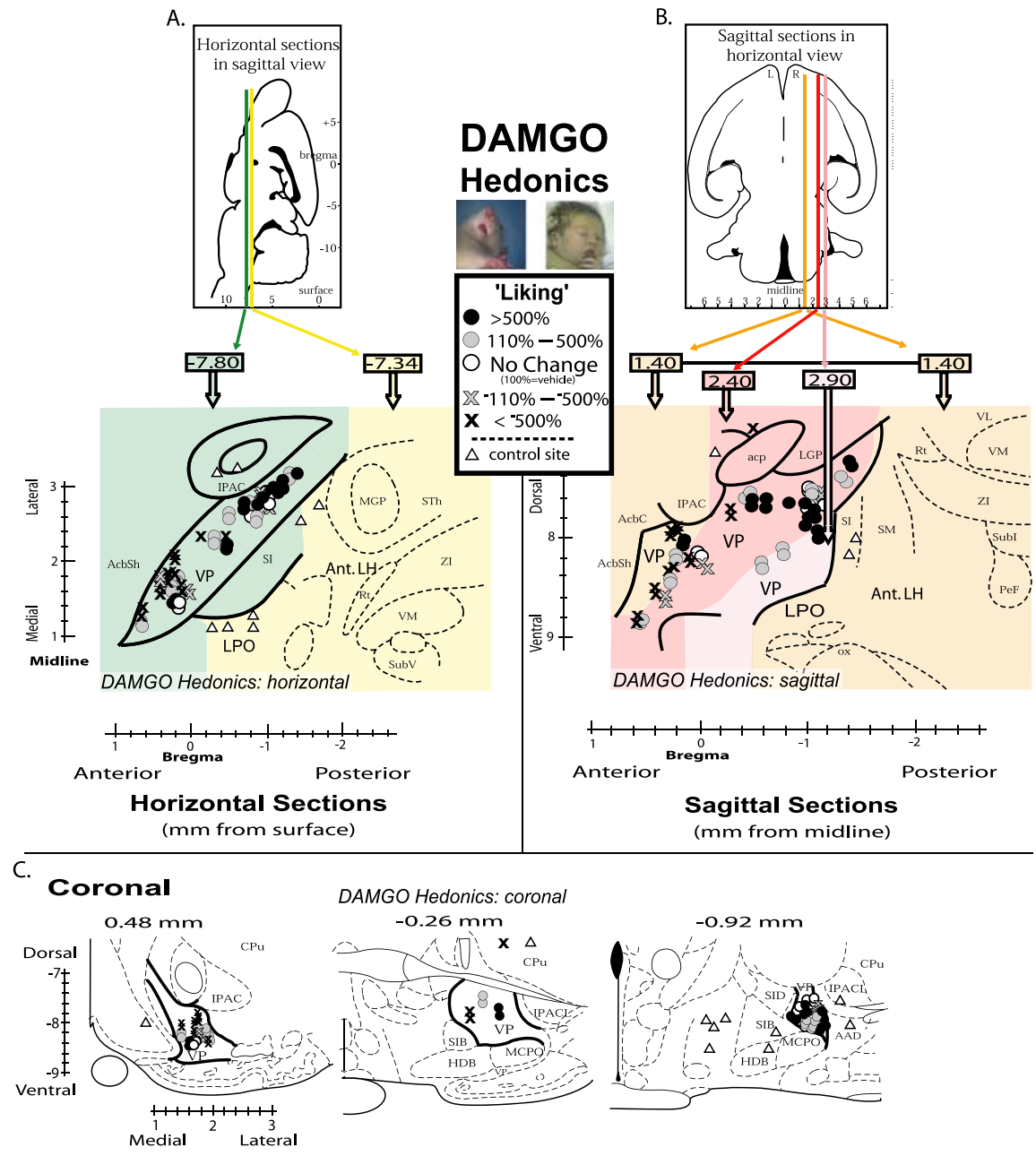

Figure 6. Pinpoint maps of DAMGO-induced "liking" effects in the VP. Each site is mapped in horizontal, sagittal, and coronal planes for three-dimensional comparison. $\boldsymbol{A}$, Horizontal map shows the entire VP best. The entire VP can be captured in a single horizontal plane, but control sites in lateral hypothalamus outside VP are at a more shallow depth. Horizontal planes of different depth of are represented by colors of background (green, $-7.80 \mathrm{~mm}$ ventral; yellow, $-7.34 \mathrm{~mm}$ ventral). Symbol locations show center of microinjection sites, and symbol types show intensity of DAMG0-caused change in sucrose-elicited hedonic "liking" reactions (percentage change from vehicle at same sites; vehicle, 100\%; circle shades denote DAMG0-induced increases; cross shades denote DAMG0-induced reductions below vehicle control levels; triangles denote control sites in brain structures outside of VP). Bilateral VP sites from left and right brains of each rat are collapsed together here into a unilateral single map of VP (right brain) for better simplicity (all doses represented). $\boldsymbol{B}$, Sagittal map of VP. Several sagittal planes of different laterality must be compressed together to represent entire VP in one sagittal map; plane literalities are represented by background colors. R, Right; $\mathrm{L}$, left (orange, $1.40 \mathrm{~mm}$; red, $2.40 \mathrm{~mm}$; pink, $2.90 \mathrm{~mm}$ ). Symbol locations and shades as in $\boldsymbol{A}$. C, Coronal maps in three separate anterior-posterior planes $(0.48,-0.26,-0.92 \mathrm{~mm})$. IPAC, Interstitial nucleus of the posterior limb of the anterior commissure; AcbSh, Nucleus accumbens shell; MGP, medial globus pallidus; STh, subthalamic nucleus; Zl, zona incerta; Rt, reticular thalamic nucleus; VM, ventromedial thalamic nucleus; SubV, ventral submedius thalamic nucleus; acp, posterior part of the anterior commissure; AcbC, nucleus accumbens core; mfb, medial forebrain bundle; SM, stria medullaris of thalamus; LGP, lateral globus pallidus; VL, ventrolateral thalamic nucleus; Subl, subincertal nucleus; PeF, perifornical nucleus; ox, optic chiasm; SIB, basal substantia innominata; $H D B$, nucleus of horizontal limb of diagonal band; MCPO, magnocellular preoptic nucleus; SID, dorsal substantia innominata; AAD, dorsal anterior amygdaloid area; IPACL, lateral part of interstitial nucleus of the posterior limb of the anterior commissure.

supplemental material), consistent with a previous study of generally central VP (Stratford et al., 1999). However, unlike DAMGO effects described above, bicuculline enhanced eating duration homogeneously throughout the VP. Bicuculline elicited similar increases in eating duration and food intake at all VP sites (Bonferonni's; $p<0.05$ for all), and the anterior, central, and posterior VP regions did not differ from each other $\left(F_{(2,62)}=0.62\right.$; $p=0.54)$ nor was there any interaction between bicuculline and microinjection site for eating duration or intake amount $\left(F_{(6,62)}=\right.$ $1.31 ; p=0.27$.
Bicuculline dose-response analyses were conducted over the entire VP (Fig. 5). Bicuculline dose microinjections increased eating duration overall in an approximately linear manner $\left(F_{(3,61)}=6.69\right.$; $p<0.01$; ANOVA for dose). The highest bicuculline dose $(0.2 \mu \mathrm{g})$ evoked more time spent eating than the lowest dose $(0.05 \mu \mathrm{g} ; p<0.05)$. Eating evoked by the middle bicuculline dose was significant $(0.1 \mu \mathrm{g} ; p<0.05)$ and did not differ from high or low dose extremes. The lowest bicuculline dose $(0.05 \mu \mathrm{g})$ did not increase eating duration above vehicle $(p>0.05)$.

Bicuculline and DAMGO microinjections, when directly compared, did not differ in the magnitude of increased eating duration evoked overall (all doses and sites included; $\left.F_{(1,67)}=0.05 ; p>0.05\right)$ (Fig. 3). However, comparison of the maximally effective doses for each drug revealed that DAMGO $(0.01 \mu \mathrm{g})$ caused slightly longer eating duration than bicuculline $(0.2$ $\mu \mathrm{g})$ in posterior $\mathrm{VP}\left(t_{(4)}=3.52 ; p<0.05\right)$. This may indicate a slight advantage for opioid neurotransmission in posterior VP for promoting maximal eating compared with GABA blockade at the same site (although both drugs increased eating well above vehicle levels at this region).

\section{Control sites outside of the VP}

Control rats with bilateral microinjection cannula placements in structures outside of the VP did not show any increases in eating duration after either DAMGO or bicuculline microinjections (anterior lateral hypothalamus, $n=6$; lateral preoptic area, $n=2$; neostriatum, $n=2$; substantia innominata, $n=1$ ) (supplemental Figs. S1, S3, available at www.jneurosci.org as supplemental material). Four rats with lateral hypothalamus or lateral preoptic area microinjection only marginally increased time spent eating after $0.01 \mu \mathrm{g}$ of $\operatorname{DAMGO}\left(F_{(1,14)}=0.40\right)$. That lack of significant effect is consistent with previous reports that bicuculline and opioid agonists in the lateral hypothalamus do not produce eating (Gosnell et al., 1986; Stratford and Kelley, 1999). A previous study did report eating after more central lateral hypothalamic infusions of morphine but used a very high dose that might have diffused to VP or other regions (Stanley et al., 1988). Similarly, we know of no reports of DAMGOinduced eating in our control sites in posterior/medial neostriatal or in substantia innominata, although DAMGO at 10 times higher dose than ours has been reported to induce eating in neostriatum at sites more anterior and dorsal than ours (Zhang and Kelley, 2000). Thus, overall, our failure to find eating effects at control sites in hypothalamus, substantia innominata, and neostriatum appears consistent with published evidence available for these sites, drugs, and doses. 
Rostrocaudal differences versus other dimensions?

Rostrocaudal differences within the VP might possibly be characterized alternatively as medial/lateral or ventral/dorsal differences, in the sense that the anterior VP has a ventral and medial placement in basal forebrain, compared with the relatively dorsal and lateral placement of posterior VP (supplemental Fig. S5, available at www. jneurosci.org as supplemental material). Thus, anterior VP features might be called ventral or medial features, and posterior VP features might be called dorsal or lateral features. However, we stress that in our mapped "liking" and eating functions, medial/lateral and dorsal/ ventral differences exist only with respect to the placement of the VP in the whole brain, based on the location of anterior and posterior poles of the VP, rather than as segregated parts within VP itself (supplemental Fig. S5, available at www.jneurosci.org as supplemental material). For example, we could detect no significant mediolateral difference within any single plane of VP for "liking" reactions (DAMGO, $F_{(1,56)}=0.50$, NS; bicuculline, $F_{(1,59)}=0.11$, NS) or eating duration (DAMGO, $F_{(1,65)}=2.22$, NS; bicuculline, $F_{(1,63)}=$ 0.68 , NS), nor did we detect a dorsoventral difference within the VP for "liking" (DAMGO, $F_{(1,53)}=0.004$, NS; bicuculline, $F_{(1,56)}=$ 0.001 , NS) or eating (DAMGO, $F_{(1,60)}=0.59$, NS; bicuculline, $F_{(1,60)}=0.89$, NS). In contrast, the anterior/posterior differences in opioid function existed as differences across subdivisions within the $\mathrm{VP}$, even when those parts of VP were accurately represented in a single plane of view (supplemental Fig. S5, available at www. jneurosci.org as supplemental material).

\section{Additional evoked behaviors}

\section{Forepaw treading: DAMGO and bicuculline}

DAMGO elicited forepaw treading behavior that resembled defensive-type or fearful behavioral treading ordinarily shown by squirrels to rattlesnakes in the wild and by lab rats to shock prods and other threatening stimuli (Owings and Coss, 1977; Treit et al., 1981; Reynolds and Berridge, 2001). Treading was characterized by coordinated forward thrusting of forepaws and spraying of bedding material toward particular objects in the environment (i.e., cage corners). A rat's orientation and its direction of shavings-kicking was not randomly positioned in space but instead specifically targeted toward corners of the chamber $\left(F_{(5,207)}=3.52 ; p<0.01\right)$ (supplemental Fig. S4, available at www.jneurosci.org as supplemental material). This directionality possibly occurred because the curved Plexiglas corners had slight visual "glitter" aspects, reflecting light back into the chamber and distorting the image of objects beyond them in the room. In other words, corners might have been perceived as distinct (and even threatening) visual stimuli. During treading bouts, a rat typically took a central position in the chamber and oriented its body to face one of the corners (sometimes switching from one corner to another during the course of a session). Treading movements by the rat were targeted directly toward the chosen corner, and the rat would vigorously push wood shavings in front of itself in the direction of the corner. Rats that exhibited both treading and eating behavior after DAMGO typically alternated between these two behaviors in 2-5 min bouts throughout the $1 \mathrm{~h}$ testing period.

Paw-treading behavior was increased by both DAMGO and bicuculline, even at doses and sites that also enhanced eating duration (Figs. 4, 5, supplemental Fig. S4, available at www. jneurosci.org as supplemental material). DAMGO microinjections in the VP increased paw treading behavior overall $\left(F_{(5,65)}=\right.$ $14.34 ; p<0.001)$ and at all doses $(p<0.05$ for each). Microinjection site was not a significant factor $\left(F_{(5,65)}=0.76 ; p>0.05\right)$, suggesting that VP subregions did not differ for DAMGO-elicited defensive treading behavior.
However, DAMGO microinjections in the VP did not elicit other defensive behaviors such as escape attempts or distress vocalizations when rats were picked up after $1 \mathrm{~h}$ of testing. This observation suggests that defensive behavior after DAMGO in the VP may have been less intense than produced in previous studies of defensive treading by accumbens shell microinjections of muscimol or DNQX (Reynolds and Berridge, 2001, 2003). Furthermore, the quantity of defensive treading behavior we observed was only $\sim 50 \%$ of treading found in those previous studies (Reynolds and Berridge, 2001, 2003). Thus, DAMGO in the VP may evoke defensive behavior at relatively moderate intensity.

Bicuculline in the $\mathrm{VP}$ also increased paw treading, again at all sites $\left(F_{(5,36)}=8.74 ; p<0.01\right)$ and all doses $(p<0.05$ for each $)$ (supplemental Fig. S4, available at www.jneurosci.org as supplemental material). All VP regions supported similar amounts of bicuculline-evoked treading $\left(F_{(5,36)}=1.27\right)$, and all bicuculline doses evoked similar increases in treading behavior over vehicle level ( $p>0.05$ for each pairwise comparison). In direct contrast to the corner-targeted DAMGO-elicited treading described above, bicuculline-elicited treading was essentially random in spatial orientation and was not directed specifically toward corners or other landmarks $\left(F_{(5,221)}=2.24 ; p>0.05\right)$ (supplemental Fig. S4, available at www.jneurosci.org as supplemental material), suggesting that bicuculline treading might be less motivationally directed to specific targets compared with DAMGOelicited treading. Bicuculline treading was also frequently mixed with digging actions (39\% of all paw treading; described below), and those blended instances of treading/digging produced a more hunched posture with a forward center of gravity compared with DAMGO-elicited treading, in which the rat sat back on its hindquarters and directed its forepaw thrusts forward. The mixture of treading with digging movements made bicuculline-elicited treading different from natural defensive treading in kinematics and posture. Bicuculline elicited less treading than DAMGO overall in a direct comparison of the drugs $\left(F_{(1,66)}=4.49 ; p<0.05\right.$; ANOVA).

\section{Digging}

Only bicuculline in the VP produced digging behavior. Digging was defined as forepaw pulling movements that scraped substrate toward the body (rather than away from the body as in defensive treading), producing a crater in the bedding underneath the rat. Bicuculline at most sites significantly enhanced digging over vehicle (bicuculline, $14.13 \pm 6.80$ SEM bouts; vehicle, $1.79 \pm 0.41$ SEM; paired $t$ test; $t_{(58)}=-1.99 ; p<0.05$ ) (supplemental Fig. S4, available at www.jneurosci.org as supplemental material). In contrast, DAMGO failed to significantly increase digging behavior above vehicle (3.00 \pm 0.61 SEM bouts; $6 \%$ of all treading) (supplemental Fig. $\mathrm{S} 4$, available at www.jneurosci.org as supplemental material).

\section{Locomotion and food carrying}

Both DAMGO and bicuculline enhanced general locomotor behavior. DAMGO enhanced cage crossing behavior (DAMGO, $61.34 \pm 9.81 \mathrm{SEM}$ crosses/h; vehicle, $30.16 \pm 2.98 ; F_{(1,65)}=8.32$; $p<0.01$ ) and rearing behavior (DAMGO, $152.34 \pm 19.41$ SEM rears/h; vehicle, $\left.72.84 \pm 8.66 ; F_{(1,65)}=12.83 ; p<0.01\right)$ at all VP subregions compared with vehicle (data not shown). Post hoc tests revealed that only the highest two doses of DAMGO (0.1, $0.25 \mu \mathrm{g})$ significantly enhanced locomotion $(p<0.05$ for both cage crossing and rearing). Bicuculline also caused locomotor activation at all VP sites and at all doses, both for rearing (bicuculline, $79.5 \pm 10.77$; vehicle, $72.84 \pm 8.66 ; F_{(1,62)}=0.55 ; p<$ 0.01 ) and cage crossing (bicuculline, $30.63 \pm 15.37$; vehicle, $\left.30.16 \pm 2.98 ; F_{(1,62)}=18.95 ; p<0.001\right)$. In addition, bicuculline 
microinjections increased food carrying behavior, in which food was picked up in the mouth, carried to another part of the chamber, and deposited (bicuculline, 9.61 \pm 2.71 SEM carries/h; vehicle, $\left.1.33 \pm 0.45 \mathrm{SEM} ; F_{(5,62)}=7.95 ; p<0.01\right)$. Bicucullineevoked food carrying was similar for all VP sites and all doses above vehicle. In contrast, DAMGO did not cause food carrying, suggesting that food carrying, as digging, is more specific to $\mathrm{GABA}_{\mathrm{A}}$ receptor activity in the VP.

\section{Discussion}

\section{VP localization of opioid-generated hedonic "liking"}

Our results demonstrate that enhancement of taste hedonic impact is especially mediated by $\mu$-opioid circuits localized in the posterior VP. The opioid site for causing increased "liking" was limited to the posterior portion of the VP that adjoins the lateral hypothalamus, caudal to the interventricular foramen and caudal to the olfactory tubercle.

In contrast, "liking" reactions to sucrose were actually suppressed by DAMGO in the anterior VP (and somewhat in the central VP) at sites rostral to the anterior limb of the anterior commissure and to the rostral tip of the globus pallidus. Therefore, $\mu$-opioid neurotransmission in the VP appears to plays bivalent roles in modulating the hedonic impact of natural sweet rewards, causing enhancement or suppression in positive hedonic impact of sweet taste depending on precise location.

Our finding that DAMGO increased hedonic "liking" only in the posterior VP pinpoints the locus of opioid circuits that generate sucrose hedonic impact in the VP and is compatible with suggestions that opioid systems in general contribute to mediating hedonic food palatability (Cooper and Kirkham, 1993; Kelley et al., 1996; Peciña and Berridge, 2000; Berridge, 2003; Levine and Billington, 2004). However, our results add a caveat that $\mu$-opioid receptor activation does not cause increased hedonic impact for sucrose at all sites in the VP and may actually suppress hedonic impact at anterior sites.

\section{Partial dissociation of opioid "liking" and eating}

DAMGO in the posterior VP also caused increased eating duration and food intake. Increased eating and increased "liking" functions therefore overlapped for opioid circuits in the posterior third of VP. However, eating elicited by DAMGO extended more rostrally than "liking" to include the central VP. Central VP microinjections of DAMGO significantly increased eating duration but tended to decrease hedonic "liking" reactions below vehicle baseline. This dissociation between eating and "liking" reactions indicates that $\mu$-opioid activation in the central VP may stimulate food intake via a nonhedonic mechanism, which seems quite distinct from the eating produced in the posterior VP that involves increased hedonic impact of taste reward. Anatomically, this "eating-without"liking"” pattern was observed throughout a central one-third portion of the VP, caudal to the anterior limb of the anterior commissure but rostral to the interventricular foramen.

In the anterior VP, DAMGO tended to suppress eating duration in correspondence with its suppression of "liking" reactions to sweet tastes. To our knowledge, this is the first demonstration that $\mu$-opioid activation actually can suppress eating behavior in any limbic brain structure where it can also activate food intake. Finally, neither eating duration nor hedonic "liking" reactions to sucrose were altered by DAMGO or bicuculline in structures dorsal, posterior, or medial to the VP such as the neostriatum, lateral hypothalamus, lateral preoptic area, or substantia innominata, indicating that our VP effects were probably not caused by drug diffusion to these other structures.
Together, these results indicate a special role for opioid circuits in the posterior VP in generating hedonic impact and appetitive motivation for food reward (Johnson et al., 1993; Panagis et al., 1995). They also demonstrate rostrocaudal gradients of motivational function in the VP, which appear similar to rostrocaudal gradients reported for other limbic structures such as nucleus accumbens shell or ventral tegmentum (although different in valence polarity) (Reynolds and Berridge, 2001, 2003; Zangen et al., 2002).

\section{Nonhedonic mediation of eating: $\mathrm{GABA}_{\mathrm{A}}$ versus $\boldsymbol{\mu}$-opioid functions}

Bicuculline blockade of VP $\mathrm{GABA}_{\mathrm{A}}$ receptors robustly increased eating duration in the $\mathrm{VP}$, consistent with the findings of bicuculline-evoked eating in the central VP (Stratford et al., 1999), but never increased (or decreased) sucrose "liking" reactions, not even in the posterior VP. Thus, GABA-related circuits for causing eating behavior appear to be more widely distributed anatomically in the VP than opioid circuits and are completely decoupled from hedonic "liking." This eating-without-"liking" effect suggests GABA blockade throughout VP stimulates intake via purely nonhedonic mechanisms. This distinction might be related to the "wanting" without "liking" evoked by dopamine and GABA manipulations in nucleus accumbens, which appear to be mediated by motivational incentive salience mechanisms that are separable from hedonic impact mechanisms (Berridge and Valenstein, 1991; Wyvell and Berridge, 2000; Reynolds and Berridge, 2002).

\section{Additional evoked behaviors}

DAMGO also evoked a behavior that was unrelated to food, namely, forepaw treading, which was similar in form to the defensive treading behavior that normal rodents emit toward a shock prod, scorpion, rattlesnake, or other threatening objects and similar also to treading patterns elicited by GABA/glutamate microinjections in nucleus accumbens shell (Owings and Coss, 1977; Treit et al., 1981; Reynolds and Berridge, 2001, 2003). Bicuculline also evoked forepaw treading behavior, but its pattern was more fragmented and mixed with other movements (e.g., digging). In cases in which eating and treading were elicited by the same microinjection, the behaviors typically alternated in bouts of several minutes of one followed by several minutes of the other throughout the hour, a pattern that is compatible with the possibility of competition between simultaneous motivational tendencies to perform each.

\section{VP physiology relating to functional gradients}

How do DAMGO and bicuculline act on VP neurons to cause changes in food reward? The VP receives afferent projections, particularly from nucleus accumbens, containing both GABA and opioid neurotransmitters (Zahm et al., 1985; Chrobak and Napier, 1993; Lavin and Grace, 1996), and VP neurons express $\mu$-opioid and $\mathrm{GABA}_{\mathrm{A}}$ receptors (Mansour et al., 1988; Chrobak and Napier, 1993; Mitrovic and Napier, 1995; Hurd, 1996; Olive et al., 1997; Napier and Mitrovic, 1999; Bengtson and Osborne, $1999,2000) . \mu$-Opioid receptors have been suggested to modulate the activity of VP neurons by opposing GABAergic input from nucleus accumbens, as well as regulating signal-to-noise effects of glutamate inputs (Napier and Mitrovic, 1999). For example, blockade of $\mathrm{GABA}_{\mathrm{A}}$ receptors and activation of $\mu$-opioid receptors produce overlapping electrophysiological effects in VP neurons (Chrobak and Napier, 1993). This pattern seems consistent with our finding that both $\mathrm{GABA}_{\mathrm{A}}$ blockade and $\mu$-opioid activation in the VP cause similar increases in food intake and some other behaviors (e.g., locomotion). However, concerning opioid media- 
tion of hedonic "liking" specifically, it appears that opioid and GABA circuits in the VP make quite different functional contributions.

Regarding opioid rostrocaudal gradients and localization of function in the VP, the underlying basis in terms of regional differences in connectivity or in local neurochemistry remains to be explained. It is worth noting regional differences that do exist in the VP, which may turn out to be relevant to our localization of functions. For example, anterior VP neurons contain more dense concentrations of presynaptic $\mu$-opioid receptors than posterior VP neurons (Olive et al., 1997), whereas the posterior VP has a higher ratio of noncholinergic to cholinergic neurons than anterior VP (Bengtson and Osborne, 2000). Also, the anterior VP may receive more inputs from accumbens shell than the posterior VP, which is lateral to the descending accumbens efferents that project along a medial forebrain trajectory (Paxinos and Watson, 1998; Usuda et al., 1998), and anterior/posterior VP regions may have differential connectivity with medial prefrontal, insular, and somatosensory cortex (Zaborszky, 2002). However, although rostrocaudal gradients of motivational function exist in the nucleus accumbens shell as well as in the VP, it is not clear at this point whether rostrocaudal gradients in accumbens and VP are causally related (Reynolds and Berridge, 2001). The relationship of the functional rostrocaudal gradients we observed in VP also deserves closer comparison to mediolateral anatomical and neurochemical gradients in VP that others have reported (Zahm and Heimer, 1988, 1990; Zahm, 1989; Churchill et al., 1990; Johnson et al., 1996; Zahm et al., 1996; Kalivas and Nakamura, 1999; Mengual and Pickel, 2004).

\section{VP roles in reward and motivation}

Our results support previous suggestions that the VP has roles in motivation for food, sex, drugs, and other rewards (Kalivas and $\mathrm{Na}-$ kamura, 1999; Zahm, 2000; Kelley and Berridge, 2002). For example, VP vasopressin has been implicated in mating behavior and social attachment in male voles (Insel and Fernald, 2004; Lim and Young, 2004), and sexual arousal in human males is accompanied by activation of regions around ventral globus pallidus that may overlap with the VP (Rauch et al., 1999). The VP also supports brain stimulation reward (Panagis et al., 1995; McBride et al., 1999) and contributes to rewarding effects of heroin, cocaine, alcohol, phencyclidine, and other drugs (Gong et al., 1997; June et al., 2003; Melendez et al., 2003; Caille and Parsons, 2004; Febo et al., 2004; Koob, 2004; Abe et al., 2005, Tang et al., 2005). Thus, the neuroanatomical and neurochemical segregation of reward/motivation functions indicated by our mapping of hedonic "liking" versus eating functions may be relevant to other rewards besides sweetness or food and may carry implications for understanding VP contributions to clinical motivational disorders, including addiction.

\section{References}

Abe S, Suzuki T, Endo K, Hori T, Arai H (2005) Effects of single and repeated phencyclidine administration on $[3 \mathrm{H}]$ flunitrazepam binding in rat brain. Prog Neuropsychopharmacol Biol Psychiatry 29:133-140.

Bengtson CP, Osborne PB (1999) Electrophysiological properties of anatomically identified ventral pallidal neurons in rat brain slices. Ann NY Acad Sci 877:691-694.

Bengtson CP, Osborne PB (2000) Electrophysiological properties of cholinergic and noncholinergic neurons in the ventral pallidal region of the nucleus basalis in rat brain slices. J Neurophysiol 83:2649-2660.

Berridge KC (2000) Measuring hedonic impact in animals and infants: microstructure of affective taste reactivity patterns. Neurosci Biobehav Rev 24:173-198.

Berridge KC (2003) Pleasures of the brain. Brain Cogn 52:106-128.

Berridge KC, Valenstein ES (1991) What psychological process mediates feeding evoked by electrical stimulation of the lateral hypothalamus? Behav Neurosci 105:3-14.
Berthoud HR (2002) Multiple neural systems controlling food intake and body weight. Neurosci Biobehav Rev 26:393-428.

Caille S, Parsons LH (2004) Intravenous heroin self-administration decreases GABA efflux in the ventral pallidum: an in vivo microdialysis study in rats. Eur J Neurosci 20:593-596.

Chrobak JJ, Napier TC (1993) Opioid and GABA modulation of accumbensevoked ventral pallidal activity. J Neural Transm Gen Sect 93:123-143.

Churchill L, Kalivas PW (1994) A topographically organized gammaaminobutyric acid projection from the ventral pallidum to the nucleus accumbens in the rat. J Comp Neurol 345:579-595.

Churchill L, Dilts RP, Kalivas PW (1990) Changes in gamma-aminobutyric acid, mu-opioid and neurotensin receptors in the accumbens-pallidal projection after discrete quinolinic acid lesions in the nucleus accumbens. Brain Res 511:41-54.

Churchill L, Zahm DS, Kalivas PW (1996) The mediodorsal nucleus of the thalamus-I. Forebrain gabaergic innervation. Neuroscience 70:93-102.

Cooper SJ, Kirkham TC (1993) Opioid mechanisms in the control of food consumption and taste preferences. In: Opioids, Pt I and II (Herz AA, Simon EJ, eds), pp 239-262. Berlin: Springer.

Cromwell HC, Berridge KC (1993) Where does damage lead to enhanced food aversion: the ventral pallidum/substantia innominata or lateral hypothalamus? Brain Res 624:1-10.

Febo M, Segarra AC, Nair G, Schmidt K, Duong TQ, Ferris CF (2004) The neural consequences of repeated cocaine exposure revealed by functional MRI in awake rats. Neuropsychopharmacology Adv Online Publ 12/22/ 04:1-8.

Gong W, Neill D, Justice Jr JB (1997) 6-Hydroxydopamine lesion of ventral pallidum blocks acquisition of place preference conditioning to cocaine. Brain Res 754:103-112.

Gosnell BA, Morley JE, Levine AS (1986) Opioid-induced feeding: localization of sensitive brain sites. Brain Res 369:177-184.

Grill H, Norgren R (1978) The taste reactivity test. I. Mimetic responses to gustatory stimuli in neurologically normal rats. Brain Res 143:263-279.

Grill HJ, Berridge KC (1985) Taste reactivity as a measure of the neural control of palatability. In: Progress in psychobiology and physiological psychology, Vol II (Sprague JM, Epstein AN, eds), pp 1-61. Orlando: Academic.

Groenewegen HJ, Berendse HW, Haber SN (1993) Organization of the output of the ventral striatopallidal system in the rat: ventral pallidal efferents. Neuroscience 57:113-142.

Groenewegen HJ, Galis-de Graaf Y, Smeets WJ (1999) Integration and segregation of limbic cortico-striatal loops at the thalamic level: an experimental tracing study in rats. J Chem Neuroanat 16:167-185.

Grove EA (1988) Neural associations of the substantia innominata in the rat: afferent connections. J Comp Neurol 277:315-346.

Heimer L, Wilson RD (1975) The subcortical projections of allocortex: similarities in the neural associations of the hippocampus, the piriform cortex and the neocortex. In: Golgi centennial symposium proceedings (Santini M, ed), pp 173-193. New York: Raven.

Heimer L, Zahm DS, Churchill L, Kalivas PW, Wohltmann C (1991) Specificity in the projection patterns of accumbal core and shell in the rat. Neuroscience 41:89-125.

Holt AG, Newman SW (2004) Distribution of methionine and leucine enkephalin neurons within the social behavior circuitry of the male Syrian hamster brain. Brain Res 1030:28-48.

Hsu SM, Raine L, Fanger H (1981) Use of avidin-biotin-peroxidase complex $(\mathrm{ABC})$ in immunoperoxidase techniques: a comparison between $\mathrm{ABC}$ and unlabeled antibody (PAP) procedures. J Histochem Cytochem 29:577-580.

Hurd YL (1996) Differential messenger RNA expression of prodynorphin and proenkephalin in the human brain. Neuroscience 72:767-783.

Insel TR, Fernald RD (2004) How the brain processes social information: searching for the social brain. Annu Rev Neurosci 27:697-722.

Johnson P, Stellar J, Paul A (1993) Regional reward differences within the ventral pallidum are revealed by microinjections of a mu opiate receptor agonist. Neuropharmacology 32:1305-1314.

Johnson P, Parente M, Stellar J (1996) NMDA-induced lesions of the nucleus accumbens or the ventral pallidum increase the rewarding efficacy of food to deprived rats. Brain Res 722:109-117.

June HL, Foster KL, McKay PF, Seyoum R, Woods JE, Harvey SC, Eiler WJ, Grey C, Carroll MR, McCane S, Jones CM, Yin W, Mason D, Cummings R, Garcia M, Ma C, Sarma PV, Cook JM, Skolnick P (2003) The reinforcing properties of alcohol are mediated by GABA(A1) receptors in the ventral pallidum. Neuropsychopharmacology 28:2124-2137. 
Kalivas PW, Nakamura M (1999) Neural systems for behavioral activation and reward. Curr Opin Neurobiol 9:223-227.

Kelley AE, Berridge KC (2002) The neuroscience of natural rewards: relevance to addictive drugs. J Neurosci 22:3306-3311.

Kelley AE, Bless EP, Swanson CJ (1996) Investigation of the effects of opiate antagonists infused into the nucleus accumbens on feeding and sucrose drinking in rats. J Pharmacol Exp Ther 278:1499-1507.

Klitenick MA, Deutch AY, Churchill L, Kalivas PW (1992) Topography and functional role of dopaminergic projections from the ventral mesencephalic tegmentum to the ventral pallidum. Neuroscience 50:371-386.

Koob GF (2004) A role for GABA mechanisms in the motivational effects of alcohol. Biochem Pharmacol 68:1515-1525.

Lavin A, Grace AA (1996) Physiological properties of rat ventral pallidal neurons recorded intracellularly in vivo. J Neurophysiol 75:1432-1443.

Levine AS, Billington CJ (2004) Opioids as agents of reward-related feeding: a consideration of the evidence. Physiol Behav 82:57-61.

Lim MM, Young LJ (2004) Vasopressin-dependent neural circuits underlying pair bond formation in the monogamous prairie vole. Neuroscience 125:35-45.

Mansour A, Khachaturian H, Lewis ME, Akil H, Watson SJ (1988) Anatomy of CNS opioid receptors. Trends Neurosci 11:308-314.

McAlonan GM, Robbins TW, Everitt BJ (1993) Effects of medial dorsal thalamic and ventral pallidal lesions on the acquisition of a conditioned place preference: further evidence for the involvement of the ventral striatopallidal system in reward-related processes. Neuroscience 52:605-620.

McBride WJ, Murphy JM, Ikemoto S (1999) Localization of brain reinforcement mechanisms: intracranial self-administration and intracranial place-conditioning studies. Behav Brain Res 101:129-152.

Melendez RI, Rodd-Henricks ZA, McBride WJ, Murphy JM (2003) Alcohol stimulates the release of dopamine in the ventral pallidum but not in the globus pallidus: a dual-probe microdialysis study. Neuropsychopharmacology 28:939-946.

Mengual E, Pickel VM (2004) Regional and subcellular compartmentation of the dopamine transporter and tyrosine hydroxylase in the rat ventral pallidum. J Comp Neurol 468:305-409.

Mitrovic I, Napier TC (1995) Electrophysiological demonstration of mu, delta and kappa opioid receptors in the ventral pallidum. J Pharmacol Exp Ther 272:1260-1270.

Mogenson GJ, Jones DJ, Yim CY (1980) From motivation to action: functional interface between the limbic system and the motor system. Prog Neurobiol 14:69-97.

Morgane PJ (1961) Alterations in feeding and drinking behavior of rats with lesions in globi pallidi. Am J Physiol 201:420-428.

Napier TC, Mitrovic I (1999) Opioid modulation of ventral pallidal inputs. Ann NY Acad Sci 877:176-201.

Olive MF, Anton B, Micevych P, Evans CJ, Maidment NT (1997) Presynaptic versus postsynaptic localization of $\mu$ and $\delta$ opioid receptors in dorsal and ventral striatopallidal pathways. J Neurosci 17:7471-7479.

Owings DH, Coss RG (1977) Snake mobbing by California ground squirrels-adaptive variation and ontogeny. Behaviour 62:50-69.

Panagis G, Miliaressis E, Anagnostakis Y, SpyrakiC (1995) Ventral pallidum self-stimulation: a moveable electrode mapping study. Behav Brain Res 68:165-172.

Paxinos G, Watson C (1998) The rat brain in stereotaxic coordinates. San Diego: Academic.

Peciña S, Berridge KC (2000) Opioid site in nucleus accumbens shell mediates eating and hedonic "liking" for food: map based on microinjection Fos plumes. Brain Res 863:71-86.

Rauch SL, Shin LM, Dougherty DD, Alpert NM, Orr SP, Lasko M, Macklin ML, Fischman AJ, Pitman RK (1999) Neural activation during sexual and competitive arousal in healthy men. Psychiatry Res 91:1-10.

Reynolds SM, Berridge KC (2001) Fear and feeding in the nucleus accumbens shell: rostrocaudal segregation of GABA-elicited defensive behavior versus eating behavior. J Neurosci 21:3261-3270.

Reynolds SM, Berridge KC (2002) Positive and negative motivation in nucleus accumbens shell: bivalent rostrocaudal gradients for GABA-elicited eating, taste "liking”/“disliking" reactions, place preference/avoidance, and fear. J Neurosci 22:7308-7320.

Reynolds SM, Berridge KC (2003) Glutamate motivational ensembles in nucleus accumbens: rostrocaudal shell gradients of fear and feeding. Eur J Neurosci 17:2187-2200.

Schallert T, Whishaw IQ (1978) Two types of aphagia and two types of sensorimotor impairment after lateral hypothalamic lesions: observations in normal weight, dieted, and fattened rats. J Comp Physiol Psychol 92:720-741.

Stanley BG, Lanthier D, Leibowitz SF (1988) Multiple brain sites sensitive to feeding stimulation by opioid agonists: a cannula-mapping study. Pharmacol Biochem Behav 31:825-832.

Steiner JE, Glaser D, Hawilo ME, Berridge KC (2001) Comparative expression of hedonic impact: affective reactions to taste by human infants and other primates. Neurosci Biobehav Rev 25:53-74.

Stratford TR, Kelley AE (1999) Evidence of a functional relationship between the nucleus accumbens shell and lateral hypothalamus subserving the control of feeding behavior. J Neurosci 19:11040-11048.

Stratford TR, Kelley AE, Simansky KJ (1999) Blockade of GABA(A) receptors in the medial ventral pallidum elicits feeding in satiated rats. Brain Res 825:199-203.

Swanson LW (2000) Cerebral hemisphere regulation of motivated behavior. Brain Res 886:113-164.

Tang X-C, McFarland K, Cagle S, Kalivas PW (2005) Cocaine-induced reinstatement requires endogenous stimulation of $\mu$-opioid receptors in the ventral pallidum. J Neurosci 25:4512-4520.

Tindell AJ, Berridge KC, Aldridge JW (2004) Ventral pallidal representation of pavlovian cues and reward: population and rate codes. J Neurosci 24:1058-1069.

Treit D, Pinel JP, Fibiger HC (1981) Conditioned defensive burying: a new paradigm for the study of anxiolytic agents. Pharmacol Biochem Behav 15:619-626.

Usuda I, Tanaka K, Chiba T (1998) Efferent projections of the nucleus accumbens in the rat with special reference to subdivision of the nucleus: biotinylated dextran amine study. Brain Res 797:73-93.

Watts AG (2000) Understanding the neural control of ingestive behaviors: helping to separate cause from effect with dehydration-associated anorexia. Horm Behav 37:261-283.

Wyvell CL, Berridge KC (2000) Intra-accumbens amphetamine increases the conditioned incentive salience of sucrose reward: enhancement of reward "wanting" without enhanced "liking" or response reinforcement. J Neurosci 20:8122-8130.

Young Jr WS, Alheid GF, Heimer L (1984) The ventral pallidal projection to the mediodorsal thalamus: a study with fluorescent retrograde tracers and immunohistofluorescence. J Neurosci 4:1626-1638.

Zaborszky L (2002) The modular organization of brain systems. Basal forebrain: the last frontier. Prog Brain Res 136:359-372.

Zahm DS (1989) The ventral striatopallidal parts of the basal ganglia in the rat. II. Compartmentation of ventral pallidal efferents. Neuroscience 30:33-50.

Zahm DS (2000) An integrative neuroanatomical perspective on some subcortical substrates of adaptive responding with emphasis on the nucleus accumbens. Neurosci Biobehav Rev 24:85-105.

Zahm DS, Heimer L (1988) Ventral striatopallidal parts of the basal ganglia in the rat: I. Neurochemical compartmentation as reflected by the distributions of neurotensin and substance P immunoreactivity. J Comp Neurol 272:516-535.

Zahm DS, Heimer L (1990) Two transpallidal pathways originating in the rat nucleus accumbens. J Comp Neurol 302:437-446.

Zahm DS, Zaborszky L, Alones VE, Heimer L (1985) Evidence for the coexistence of glutamate decarboxylase and Met-enkephalin immunoreactivities in axon terminals of rat ventral pallidum. Brain Res 325:317-321.

Zahm DS, Williams E, Wohltmann C (1996) Ventral striatopallidothalamic projection: IV. Relative involvements of neurochemically distinct subterritories in the ventral pallidum and adjacent parts of the rostroventral forebrain. J Comp Neurol 364:340-362.

Zangen A, Ikemoto S, Zadina JE, Wise RA (2002) Rewarding and psychomotor stimulant effects of endomorphin-1: anteroposterior differences within the ventral tegmental area and lack of effect in nucleus accumbens. J Neurosci 22:7225-7233.

Zhang M, Kelley AE (2000) Enhanced intake of high-fat food after striatal mu-opioid stimulation: microinjection mapping and fos expression. Neuroscience 99:267-277. 